\title{
ARQUEOMETRIA APLICADA À CONSERVAÇÃO DO PATRIMÔNIO ARQUEOLÓGICO METÁLICO: UM ESTUDO DE CASO DO SÍTIO FUNERÁRIO DE SÃO GONÇALO GARCIA, RIO DE JANEIRO
}

ARCHEOMETRY APPLIED TO THE CONSERVATION OF METALLIC ARCHAEOLOGICAL HERITAGE: A CASE STUDY OF THE FUNERARY SITE OF SÃO GONÇALO GARCIA, RIO DE JANEIRO

Guadalupe do Nascimento Campos

Marcus Granato

Antonieta Middea

Ricardo Tadeu Lopes

Como citar este artigo:

CAMPOS, Guadalupe do Nascimento; GRANATO, Marcus; MIDDEA Antonieta; LOPES Ricardo Tadeu. Arqueometria aplicada à conservação do patrimônio arqueológico metálico: um estudo de caso do sítio funerário de São Gonçalo Garcia, Rio de Janeiro. In: Cadernos do Lepaarq, v. XV, n.30., p. 290-314, Jul-Dez. 2018. 


\title{
Arqueometria aplicada à conservação do patrimônio arqueológico metálico: um estudo de caso do sítio funerário de São Gonçalo Garcia, Rio de Janeiro
}

\author{
Guadalupe do Nascimento Campos ${ }^{\mathrm{a}}$ \\ Marcus Granato ${ }^{\mathrm{b}}$ \\ Antonieta Middea $^{\mathrm{c}}$ \\ Ricardo Tadeu Lopes ${ }^{\mathrm{d}}$
}

\begin{abstract}
Resumo: $O$ presente trabalho apresenta alguns dos resultados obtidos no âmbito do projeto de pesquisa Conservação e Caracterização Microanalítica de Objetos Arqueológicos Metálicos, desenvolvido no Museu de Astronomia e Ciências Afins - MAST. O projeto tem como objetivo principal estabelecer metodologias de caracterização e conservação do patrimônio arqueológico metálico. Os artefatos selecionados para o estudo de caso são provenientes do Sítio Funerário da Igreja São Gonçalo Garcia (região central do Rio de Janeiro), relacionados aos séculos XVIII e XIX. Para os exames arqueométricos, foram empregadas as seguintes técnicas de caracterização: radiografia digital e microtomografia computadorizada de raios $\mathrm{X}$, microscopias estereoscópica e eletrônica de varredura, espectroscopia de energia dispersiva(MEV/EDS) e difratometria de raios X. Foram obtidas informações sobre a composição dos artefatos (fase metálica e alguns produtos de corrosão), detalhes da morfologia em 3D não visíveis a olho nu, extensão da mineralização, dentre outros aspectos.
\end{abstract}

\section{Palavras Chave:}

Arqueometria; Conservação; Patrimônio Arqueológico; Artefatos Metálicos.

\begin{abstract}
This paper presents some of the achieved results in the "Microanalytical Conservation and Characterization of Metallic Archaeological Objects" research project, developed at the Museum of Astronomy and Related Sciences - MAST. The project's main goal is to establish methodologies for characterization and conservation of the metallic archaeological heritage. The artifacts selected for the case study are from the Funeral Site at São Gonçalo Garcia's Church (Rio de Janeiro's central region), related to the 18 th and 19th centuries. For the archaeometric examinations, the following characterization techniques were employed: digital radiography and $\mathrm{X}$ ray microtomography, stereoscopic and scanning electron microscopy, energy-dispersive X ray spectroscopy (SEM / EDS) and X ray diffraction. Results were obtained about the artifacts's composition (metallic phase and some corrosion products), 3D morphology details invisible to the naked eye, and the extent of the mineralization, among other aspects.
\end{abstract}

\section{Keywords:}

Archeometry; Conservation; Archaeological Heritage; Metallic Artefacts.

\footnotetext{
$\boldsymbol{a}$ Museóloga pela Universidade Federal do Estado do Rio de Janeiro (UNIRIO), Brasil; Arqueóloga, M.Sc. e D.Sc. em Engenharia Metalúrgica e de Materiais pela Pontifícia Universidade Católica do Rio de Janeiro (PUC-RJ), Brasil. Pesquisadora colaboradora do Museu de Astronomia e Ciências Afins (MAST), Brasil. Professora Permanente do Mestrado Profissional em Preservação de Acervos de Ciência e Tecnologia do Museu de Astronomia e Ciências Afins (MAST), Brasil. Os resultados de pesquisa aqui apresentados tiveram o apoio financeiro da Fundação de Amparo à Pesquisa do Estado do Rio de Janeiro (FAPERJ), Brasil; e do Conselho Nacional de Desenvolvimento Científico e Tecnológico (CNPq), Brasil. Email: guadalupecampos@mast.br

$\boldsymbol{b}$ Engenheiro metalúrgico pela Universidade Federal do Rio de Janeiro (UFRJ), Brasil; mestre e doutor em Engenharia Metalúrgica pelo Instituto Alberto Luiz Coimbra de Pós-Graduação e Pesquisa de Engenharia, a unidade da Universidade Federal do Rio de Janeiro (COPPE/UFRJ), Brasil; pesquisador do Museu de Astronomia e Ciências Afins (MAST), Brasil; professor do programa de Pós-Graduação em Museologia e Patrimônio pela Universidade Federal do Estado do Rio de Janeiro e Museu de Astronomia e Ciências Afins (UNIRIO/MAST), Brasil; e do Mestrado Profissional em Preservação do Patrimônio de C\&T pelo Museu de Astronomia e Ciências Afins (MAST), Brasil; bolsista de produtividade 1C do Conselho Nacional de Desenvolvimento Científico e Tecnológico (CNPq), Brasil; líder do Grupo de Pesquisa Museolo-gia e Preservação de Acervos Culturais.marcus@mast.br

$c$ Engenheira Química pela Universidade Federal Rural do Rio de Janeiro (UFRRJ), Brasil; com Mestrado e Doutorado em Ciência e Tecno-logia de Polímeros pela Universidade Federal do Rio de Janeiro (UFRJ), Brasil. Atualmente faz parte do Setor de Caracterização Tecnoló-gica (SCT) do Centro de Tecnologia Mineral (CETEM), Brasil. E-mail: amiddea@cetem.gov.br $\boldsymbol{d}$ Possui graduação em Física pela Universidade Federal do Paraná (UFPR), Brasil; mestrado e doutorado em Engenharia Nuclear pela Universidade Federal do Rio de Janeiro (UFRJ), Brasil. Atualmente é professor titular da Universidade Federal do Rio de Janeiro (UFRJ), Brasil.
} 


\section{INTRODUÇÃO}

Os artefatos arqueológicos metálicos têm especificidades que diferem daquelas relativas aos demais tipos de objetos, devido às transformações, principalmente, eletroquímicas, a que estão sujeitos por permanecerem enterrados no solo ou submersos na água. Nessas condições, geralmente, ocorre um processo denominado de corrosão, que transforma os metais em óxidos, sulfatos carbonatos, dentre outros compostos (CAMPOS; GRANATO, 2017). Esse processo se inicia a partir das superfícies dos artefatos (SELWYN, 2004), podendo ocasionar, muitas vezes, alterações substanciais como a mineralização parcial ou total, modificando sua morfologia original (CAMPOS; GRANATO, 2015).

Grande parte dos artefatos arqueológicos já poderia estar em processo de deterioração natural, durante seu uso corrente, antes mesmo do período em que estiveram enterrados ou submersos (BRADLEY, 2001). Entretanto, as alterações resultantes das interações meio-superfície do artefato podem se intensificar no espaço de tempo em que estiveram enterrados/ submersos, dependendo das propriedades químicas e físicas do solo/água circundante. Essas propriedades são determinantes, pois a presença de cloretos, o pH do meio, umidade, existência de compostos orgânicos, de microrganismos e de fertilizantes, são alguns dos fatores que influenciam na velocidade de corrosão (BERTHOLON, 2007). Nesse contexto, após um período enterrados/submersos, de um modo geral, os artefatos acabam atingindo um estado de equilíbrio com as condições de contorno (RODGERS, 2004). Portanto, ao serem coletados, são retirados desse estado de equilíbrio, o que pode acelerar o processo de deterioração, especialmente devido ao contato com o oxigênio do ar e à possível elevação nos níveis de umidade relativa (LOGAN, 2007). Dessa forma, a pesquisa arqueológica deve, assim, abranger estudos e medidas de conservação que minimizem a deterioração dos artefatos para garantir sua existência mais longa (CRONYN, 2001; (MURDOCK et al., 2001).

Os procedimentos de conservação realizados nos artefatos arqueológicos não visam ao retorno dos seus aspectos originais, mas sim estabilizá-los e, dessa forma, permitir que sejam preservados para as gerações futuras. Logo, artefatos não devem ser desamassados e as pátinas estáveis não necessitam de remoção, pois, além de terem uma função protetiva, são elementos que fazem parte da trajetória do artefato, fornecendo informações significativas para a pesquisa arqueológica. Frequentemente, o controle ambiental adequado nos espaços de guarda pode evitar a continuidade da corrosão e, assim, tratamentos interventivos se tornam desnecessários (WATKINSON, 2010).

Na preservação dos artefatos metálicos, é importante aprofundar o conhecimento, como a identificação da constituição dos materiais que os compõem (metal e suas ligas) e dos produtos de corrosão. Para tanto, a utilização de técnicas arqueométricas se faz necessária, pois são importantes ferramentas usadas para auxiliar no diagnóstico do estado de conservação dos artefatos em estudo. Essas técnicas proporcionam conhecimento sobre o processo de corrosão propriamente dito, permitindo identificar as possíveis causas da degradação dos artefatos. Além disso, possibilitam a identificação de antigas técnicas de fabricação (REHDER, 1995), definindo com mais precisão os métodos mais adequados a serem utilizados na sua conservação (CAMPOS; GRANATO, 2015). Por conseguinte, tanto as informações referentes às técnicas empregadas, que dizem respeito ao período de fabricação, morfologia e funções, quanto os simbolismos e significados atribuídos aos artefatos auxiliam na construção de narrativas sobre os variados aspectos dos grupos sociais referentes ao sítio arqueológico estudado (BERTHOLON, 2007).

O presente estudo de caso está relacionado com resultados obtidos no âmbito do projeto de pesquisa citado abaixo, referente à utilização de técnicas arqueométricas não invasivas aplicadas a um conjunto de artefatos metálicos não-ferrosos provenientes do Sítio Funerário Igreja São Gonçalo Garcia e São Jorge, situado no centro da cidade do Rio de Janeiro. 
Nesse caso, não foi possível a retirada de amostras para realizar uma caracterização mais completa, o que permitiria obter resultados mais aprofundados sobre os artefatos, principalmente sobre o bulk (parte interna do material). Contudo, a combinação dos resultados entre as técnicas não invasivas possibilitou obter informações relevantes, para um diagnóstico mais preciso sobre os procedimentos adequados a serem realizados nos artefatos, sem a necessidade da retirada de amostra.

\section{PROTOCOLO DE PRESERVAÇÃO DO PATRIMÔNIO ARQUEOLÓGICO METÁLICO}

A preservação do patrimônio arqueológico metálico seguindo metodologias científicas e empregando técnicas arqueométricas ainda é um campo restrito no Brasil. Abrange conhecimentos de disciplinas distintas como Museologia, Conservação, Arqueologia, Ciência dos Materiais e Metalurgia. Nessa conjuntura, foi estruturado o projeto de pesquisa intitulado Conservação e Caracterização Microanalítica de Objetos Arqueológicos Metálicos, desenvolvido no Museu de Astronomia e Ciências Afins - MAST. Para a sua realização, foram estabelecidas parcerias do MAST com outras instituições de pesquisa no país, como o Centro de Tecnologia Mineral - CETEM, a Pontifícia Universidade Católica PUC-Rio e o Instituto Alberto Luiz Coimbra de Pós-Graduação e Pesquisa de Engenharia - COPPE/UFRJ (CAMPOS; GRANATO, 2015). Essas colaborações possibilitaram a realização de procedimentos analíticos diversos, determinando o estabelecimento de um protocolo com base científica, específico para coleta, manuseio, documentação, conservação, acondicionamento e caracterização de artefatos arqueológicos metálicos provenientes de ambientes terrestres. Os procedimentos e as técnicas analíticas utilizadas tiveram o objetivo de responder a questões referentes à pesquisa arqueológica, à pesquisa dos materiais de acondicionamento e à conservação dos artefatos, com intuito de serem preservados por um período maior. Um dos produtos desse projeto é um material didático destinado a arqueólogos, conservadores e museólogos, relacionado aos artefatos arqueológicos de origem metálica, compreendendo os procedimentos relativos a todas as etapas da pesquisa arqueológica (CAMPOS; GRANATO, 2015).

O protocolo é constituído de práticas de conservação, onde se enfatiza a importância de conservadores capacitados para realização de procedimentos de estabilização e consolidação dos artefatos (PEDELI, 2013; CHILDS \& SULLIVAN, 2003; ROTROFF, 2001). Aconselha o mínimo de intervenção, pois qualquer procedimento empregado, mesmo que se enquadre em ações removíveis, pode ocasionar interferências ou reações com os materiais componentes dos artefatos (ROBBIOLA, 1997), distorcendo a interpretação de alguns resultados das análises que possam ser realizadas no futuro.

Também destaca a elaboração de fichas individuais para cada artefato, com informações sobre o peso, medida, fotografias e anotações coletadas nos exames visuais e arqueométricos e dos procedimentos de conservação realizados. Sugere que os artefatos de origem terrestre devam ser limpos mecanicamente, com cuidado e sem pressão. Apenas com objetivo de retirar a camada de sedimento solta, por escovação a seco ou aspiração, evitando o uso de ácidos e a retirada das pátinas. Procura-se, dessa forma, não perder informações arqueológicas, tecnológicas e artísticas dos artefatos, que podem ocorrer com a limpeza excessiva e o uso de tratamentos químicos inadequados (BERTHOLON, 2007). Para o acondicionamento, devem-se utilizar materiais inertes junto com absorventes de umidade (PAÏN, 2012).

Recomenda-se, sempre que possível, a utilização de técnicas não invasivas (sem a retirada de amostras) para a caracterização microanalítica. Por exemplo, a radiografia permite observar a estrutura, visualizar a técnica de fabricação e a montagem do artefato, e determinar a sua integridade interna (ANTELO; BUESO; GABALDON; COSTEA, 2010), propiciando visualizar inscrições, decorações e intervenções posteriores à sua fabricação, não visíveis a olho nu, que estão 
abaixo dos produtos de corrosão (JONES, 2006). Possibilita também verificar a extensão da mineralização e auxiliar no processo de limpeza mecânica, diferenciando a morfologia da peça com as zonas mineralizadas, e auxiliando no diagnóstico do seu estado de conservação (MEYER-ROUDET, 1999).

A radiografia digital direta é a técnica que utiliza um detector plano, que é um dispositivo eletrônico que converte radiação ionizante incidente em uma matriz com sinal analógico que, posteriormente, é digitalizada e transferida para um computador, gerando uma imagem digital. Esses detectores podem ser de conversão direta ou indireta e são capazes de exibir as imagens em tempo real.

A microtomografia por transmissão de raios X (microCT) permite visualizar detalhes de fabricação e decoração não visíveis a olho nu, sem qualquer intervenção física, o que possibilita a reconstituição minuciosa desses artefatos, o registro visual preciso em alta resolução da morfologia e das condições do artefato como recebido. Dessa forma, a microtomografia, como ferramenta importante de preservação de documentação do artefato, auxiliará no processo de conservação do mesmo.

Outras técnicas não invasivas indicadas são a difratometria de raios X, para caracterizar os compostos presentes nas superfícies das peças, e a microscopia eletrônica de varredura, acoplada à espectroscopia de energia dispersiva EDS, para identificar e mapear os elementos presentes em determinadas regiões da superfície dos artefatos, assim como observar a morfologia dos produtos de corrosão (CILIBERTO; SPOTO, 2000). Entretanto, quando o artefato apresentar alguma ruptura que possibilite a retirada de uma amostra, o protocolo recomenda a complementação com outras técnicas que se mostrem necessárias e que precisem de uma amostra do artefato para sua realização.

O protocolo não se constitui de receitas genéricas para procedimentos e tratamentos em grande escala, pois existem variações que devem levar em consideração as especificidades de cada artefato, através de uma avaliação preliminar. É importante ressaltar que não é indicado o emprego de receitas genéricas para o tratamento em grande escala, pois cada artefato possui características particulares (COSTA, 2008) que, muitas, vezes determinam alterações nas intervenções.

Após realizar os procedimentos estabelecidos no protocolo, salienta-se a importância do frequente monitoramento dos artefatos, nas reservas técnicas, nos museus e nas instituições de guarda. As estratégias de conservação preventiva como a climatização do ambiente de guarda, com o controle da umidade relativa, são fundamentais, para evitar a aceleração do processo de deterioração desses artefatos.

\section{SÍTIO FUNERÁRIO IGREJA SÃO GONÇALO GARCIA}

A pesquisa arqueológica, cujos resultados serão aqui apresentados, foi desenvolvida no antigo espaço funerário da Igreja de São Gonçalo Garcia, área que pertence atualmente à Biblioteca Pública do Estado do Rio de Janeiro, a recente Biblioteca Parque - BPE, situada na Praça da República, no âmbito do projeto para sua modernização. Inaugurada em 1761, de irmandade dedicada ao padroeiro dos homens pardos, foi edificada em uma área periférica da cidade, conhecida como Pequena África (LESSA; CAMPOS; TAVARES, 2016). Em 1854, como a igreja da Irmandade de São Jorge estava muito degradada, se uniu à Irmandade da Igreja de São Gonçalo Garcia, tornando-se a Igreja de São Gonçalo Garcia e São Jorge (CARVALHO, 2009). Com o passar dos anos, a Igreja ficou conhecida pela população apenas como Igreja de São Jorge.

Nas escavações, foram reveladas estruturas arquitetônicas que possivelmente correspondem ao limite do cemitério e do terreno original da igreja de São Gonçalo Garcia. Também foram evidenciados seis enterramentos primários e um 
enterramento secundário, onde se estima um número mínimo de 27 adultos e 5 crianças. No Rio de Janeiro, desde o período colonial, os enterramentos eram realizados nos espaços funerários (dentro e no entorno) de igrejas, denominados de campos santos, e foram comumente realizados até o ano de 1850 (COARACY, 2008). Portanto, conclui-se que os enterramentos revelados nas escavações pertençam apenas à Irmandade São Gonçalo Garcia e não ao período a partir da junção com a Irmandade de São Jorge. Na pesquisa histórica, realizada nos documentos da Cúria, referentes aos enterramentos na Igreja, foi possível verificar, dentre os 376 sepultamentos efetuados na parte externa (adros), a presença de 116 escravizados africanos, 32 forros e 14 livres que foram sepultados entre os anos de 1791 e 1849 (LESSA; CAMPOS; TAVARES, 2016). Dessa forma, os registros históricos embasam a possibilidade de que alguns dos enterramentos evidenciados fossem de trabalhadores pobres afrodescendentes ou mesmo de escravizados ou negros forros (CAMPOS, 2015). A Figura 1, a seguir, apresenta uma imagem desses enterramentos primários, que possivelmente são associados aos escravizados africanos, de acordo com os resultados das análises da bioarqueologia.

Os materiais coletados nas escavações foram os mais diversos, como: cerâmicas, fragmentos de garrafas de vidro, restos alimentares, louça europeia dos séculos XVII, XVIII e XIX, cachimbos e contas associados aos escravizados africanos (CAMPOS, 2015). Destacam-se os acompanhamentos dos enterramentos (botões de osso e de metal, medalhas, alfinetes, fragmentos de tecido com metal). Como esses materiais são representativos e significativos para o estudo dos sepultamentos, os mesmos foram selecionados para o presente estudo de caso.

A seguir, serão apresentados os procedimentos experimentais utilizados nas pesquisas realizadas com os artefatos selecionados para, em seguida, mostrar e analisar os dados produzidos.

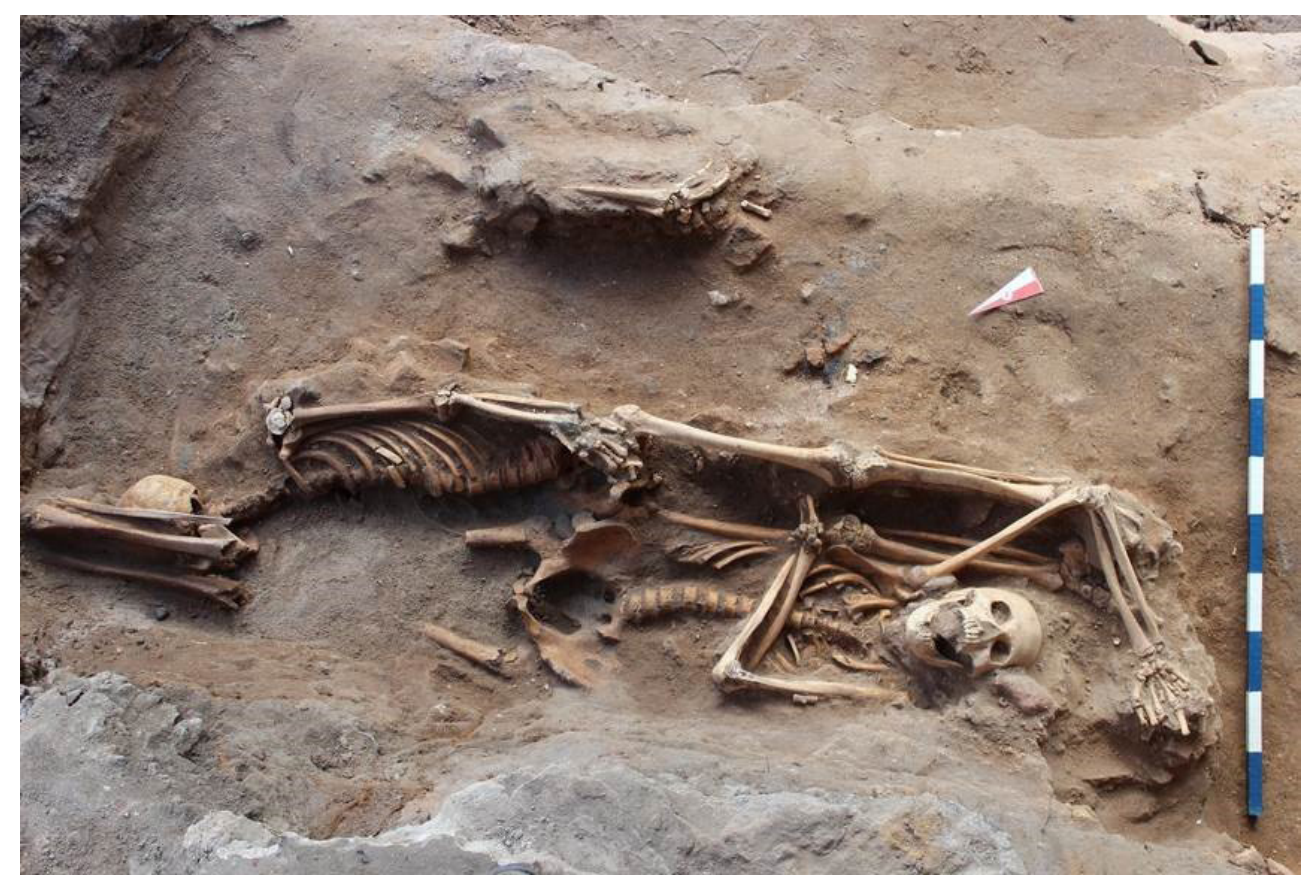

Figura 1 - Sítio Funerário Igreja São Gonçalo Garcia. Enterramentos primários associados aos escravizados africanos. Foto: Filipe Coelho, 2013 


\section{PROCEDIMENTOS EXPERIMENTAIS}

\section{Amostras selecionadas}

Após o exame macroscópico da coleção estudada, foram selecionados 15 artefatos, por sua singularidade e estado de conservação, para a realização dos exames arqueométricos. Para o presente artigo, os artefatos não ferrosos escolhidos, por representarem a coleção, foram um colchete, um botão, um crucifixo, que são imagens características, as quais são apresentadas a seguir, na Figura 2 (a, b e c).
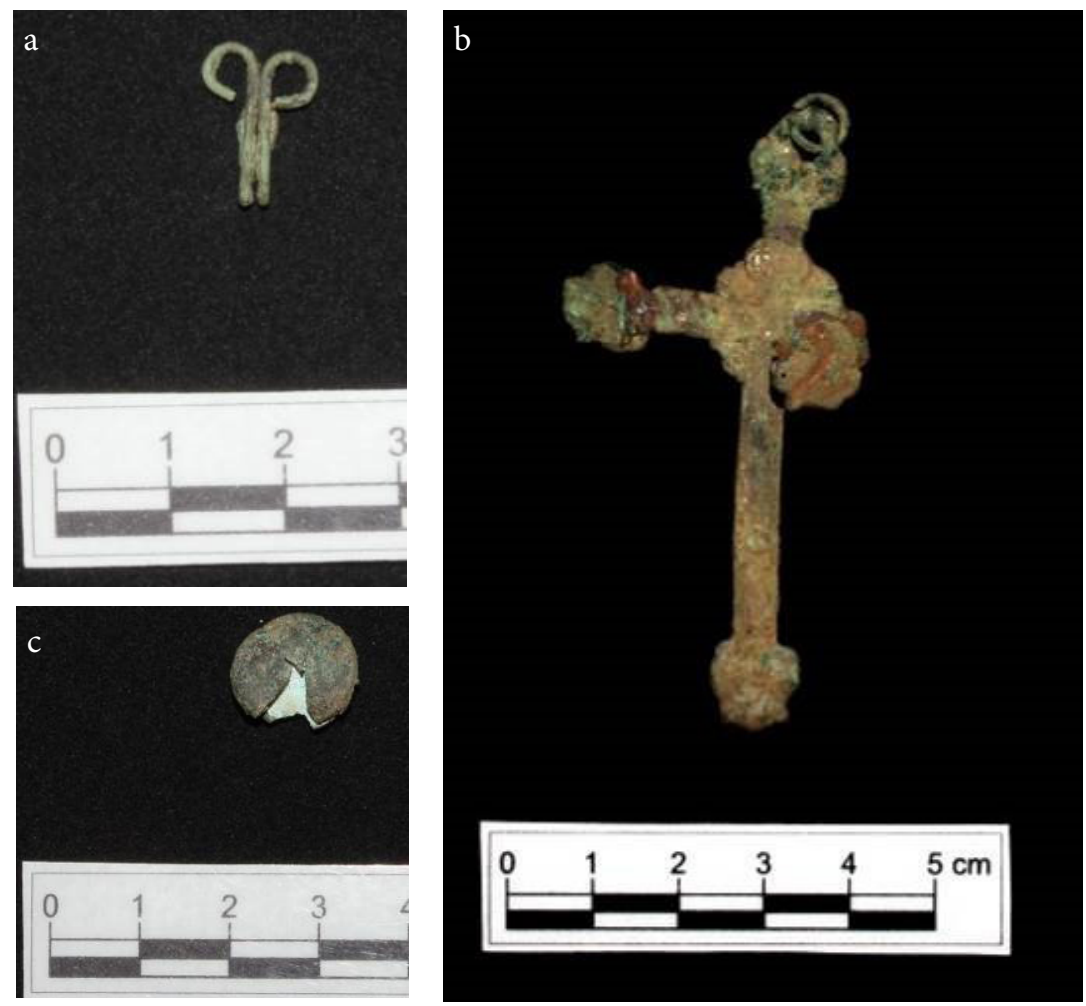

Figura 2 - Artefatos metálicos não ferrosos do Sítio Funerário Igreja São Gonçalo Garcia. a) colchete; b) crucifixo e c) botão. Fotos: Tuca Marques, 2013

\section{Métodos Analíticos}

Para a caracterização das peças supracitadas, foram utilizadas técnicas não invasivas. Não foi possível a retirada de amostras para a realização da metalografia, que permitiria a caracterização da microestrutura dos componentes metálicos originais. Dessa forma, as análises focaram na caracterização das superfícies dos artefatos, com o objetivo de visualizar a espessura das camadas de produtos de corrosão, a sua constituição e composição, além da estrutura do artefato.

Para o exame macroscópico das peças, foi usado o Estereomicroscópio Stemi DV4 da Zeiss. Em seguida, foram utilizadas diversas técnicas não invasivas como radiografia digital, microtomografia de raios X, microscopia eletrônica de varredura/EDS e difratometria de raios X. Ao final das análises, foi possível descrever visualmente conexões entre os resultados macroscópicos e os microscópicos, para relacioná-los com os produtos de corrosão identificados.

Para a Radiografia Digital Direta, foram utilizados um equipamento de raios X de potencial constante, YXLON, com tensão máxima de $160 \mathrm{kV}$ e corrente de 1 a $2 \mathrm{~mA}$, com tamanho focal de $1 \mathrm{~mm}$, e um detector tipo flat panel de Silício Amorfo e GOS (oxissulfeto de Gadolínio), GE, com área ativa de 200 x 200 mm, formato da imagem 1024 x 1024, tamanho de pixel $200 \mu \mathrm{m}$, range dinâmico de 14 bits. 
Para a microtomografia computadorizada 3D de alta resolução (microCT), foi utilizado um microtomógrafo do modelo 1173 da Skyscan-Bruker, que tem 8W de potência, com energia variável em um intervalo de 40 a $130 \mathrm{KV}$ e um detector flat panel (2240x2240) pixels. Também foi empregado um filtro de cobre de 1,0mm de espessura com o objetivo de reduzir a contribuição dos fótons de baixa energia e, assim, minimizar o efeito de endurecimento de feixe. A matriz de pixel do detector escolhida foi de (1120x1120) pixels. As projeções foram obtidas em um ângulo total de $360^{\circ}$ e 3 frames a cada passo de rotação de $1^{\circ}$. Após o processo de aquisição, as imagens foram reconstruídas. Esse processo foi feito utilizando-se os programas Nrecon ${ }^{\circledR}$ (versão 1.6.9.4) e InstaRecon (versão 1.3.9.2). Esses softwares de reconstrução possibilitam a escolha de parâmetros que geram melhor qualidade de imagem. Para cada amostra, foi feito o fine tuning e foi selecionada a melhor imagem obtida após a escolha de cada parâmetro. Após a reconstrução das imagens das amostras, foram usados dois programas de análise de imagens, o CTvox ${ }^{\circledR}$ (versão 2.6.0), para visualização das imagens em 3D, e o DataViewer ${ }^{\circledR}$ (versão 1.5.0), que permite a obtenção de três vistas ortogonais de qualquer posição escolhida na amostra: corte transaxial (plano x-y), corte coronal (plano $\mathrm{x}-\mathrm{z}$ ) e corte sagital (plano z-y).

Os artefatos foram analisados por dois microscópios eletrônicos de varredura com espectroscopia de dispersão de energia - MEV/EDS e ambos apresentaram tamanhos adequados para inserção dos artefatos no porta-amostra, de forma a viabilizar a realização das análises sem coleta de amostra. Os dois equipamentos usados foram o Tm3030Plus da Hitachi com EDS Quantax 70 da Bruker e um FEI QUANTA 400 com EDS Quantax 800 da Bruker.

Os difratogramas de raios X (DRX) das amostras também foram coletados em dois equipamentos:

Bruker-D4 Endeavor, nas seguintes condições de operação: radiação Co Ka $(35 \mathrm{kV} / 40 \mathrm{~mA})$, velocidade do goniômetro de $0,02 \mathrm{o} 2 \Theta$ por passo com tempo de contagem de 1 segundo por passo e coletados de 5 a $80^{\circ} 2 \Theta$ e;

Bruker-AXS D8, radiação Cu Ka $(40 \mathrm{kV} / 25 \mathrm{~mA})$; no range angular $2 \Theta$ de $5^{\circ}-105^{\circ}$, com passos de $0,01^{\circ}$

As interpretações qualitativas de espectro foram efetuadas por comparação com padrões contidos no banco de dados PDF02 (ICDD, 2006) em software Bruker AXS Diffrac.Plus.

\section{APRESENTAÇÃO E ANÁLISE DE RESULTADOS}

Em seguida, serão apresentados e analisados os resultados obtidos para cada artefato selecionado, nas diferentes técnicas já mencionadas.

\section{Colchete}

A Figura 3, mostrada a seguir, é uma macrografia do colchete obtida no microscópio estereoscópico. Nessa imagem, podem-se observar diferentes tonalidades de verde (claro e escuro) presentes na superfície da peça e a espessura dos produtos de corrosão do gancho esquerdo do colchete. Através do exame visual, verifica-se que cada cor dos produtos de corrosão corresponde a um composto específico. Nota-se que há alteração da morfologia da peça, onde o gancho esquerdo juntou-se ao corpo do colchete. 


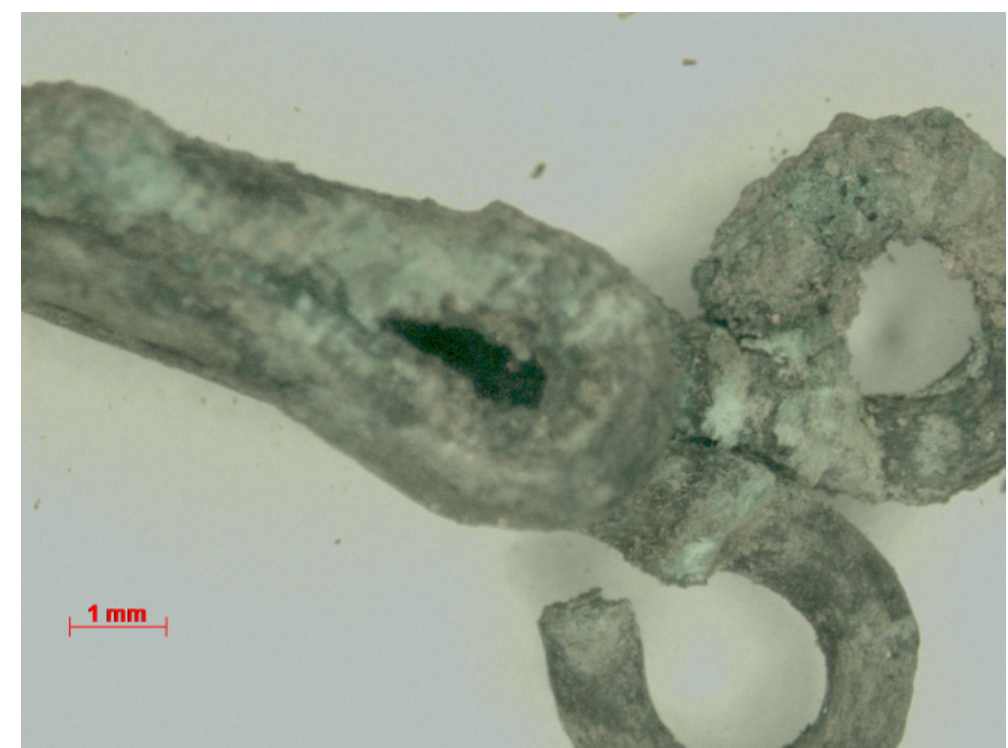

Figura 3 - Imagem obtida através do microscópio estereoscópico do colchete, mostrando produtos de corrosão de diferentes tons de verde e avermelhado

A Figura 4, mostrada a seguir, é uma imagem radiográfica do colchete, na qual pode-se observar a extensão da mineralização e a sua morfologia original.

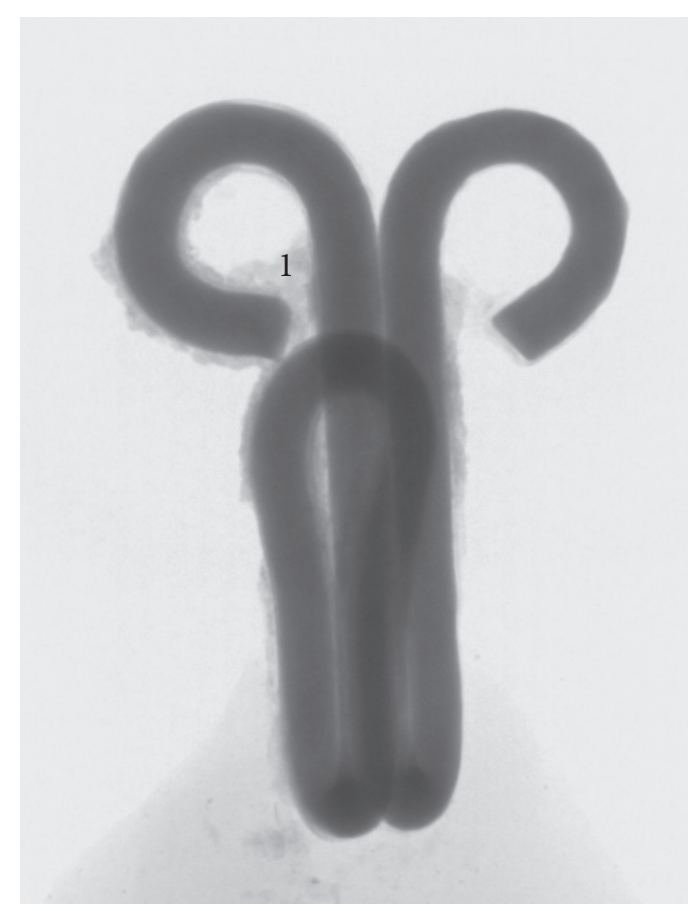

Figura 4 - Imagem de uma radiografia positiva do colchete. O Ponto 1 indica a região mais clara, de um material de menor densidade, relacionada a espessura do produto de corrosão

Verifica-se que a área mais clara (1), de um material de menor densidade, está relacionada com a espessura do produto de corrosão. As áreas escuras correspondem à fase metálica e à morfologia original do colchete.

A Figura 5, a seguir, é uma imagem de microCT do colchete, gerada pelo programa CTvox, mostrando uma reconstituição fidedgina em 3D da peça, sem a presença dos produtos de corrosão, não perceptíveis a olho nu. 


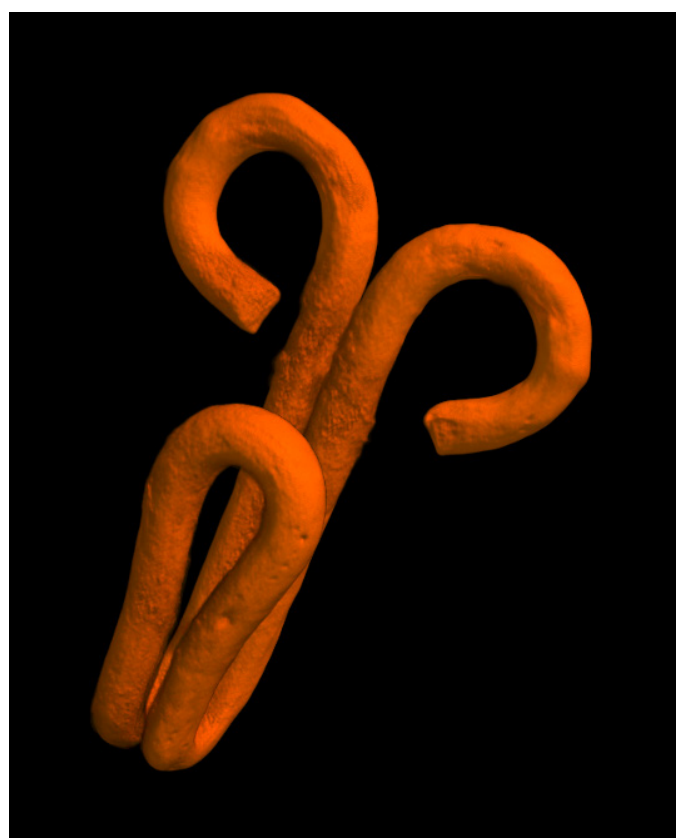

Figura 5 - Imagem em 3D gerada pelo programa CTvox do colchete, mostrando a sua morfologia sem a camada de produto de corrosão

A Figura 6 ( $\mathrm{a}$ e b) mostra o aspecto morfológico da superficie do colchete com imagens obtidas no MEV em elétrons secundários com ampliações diferentes.
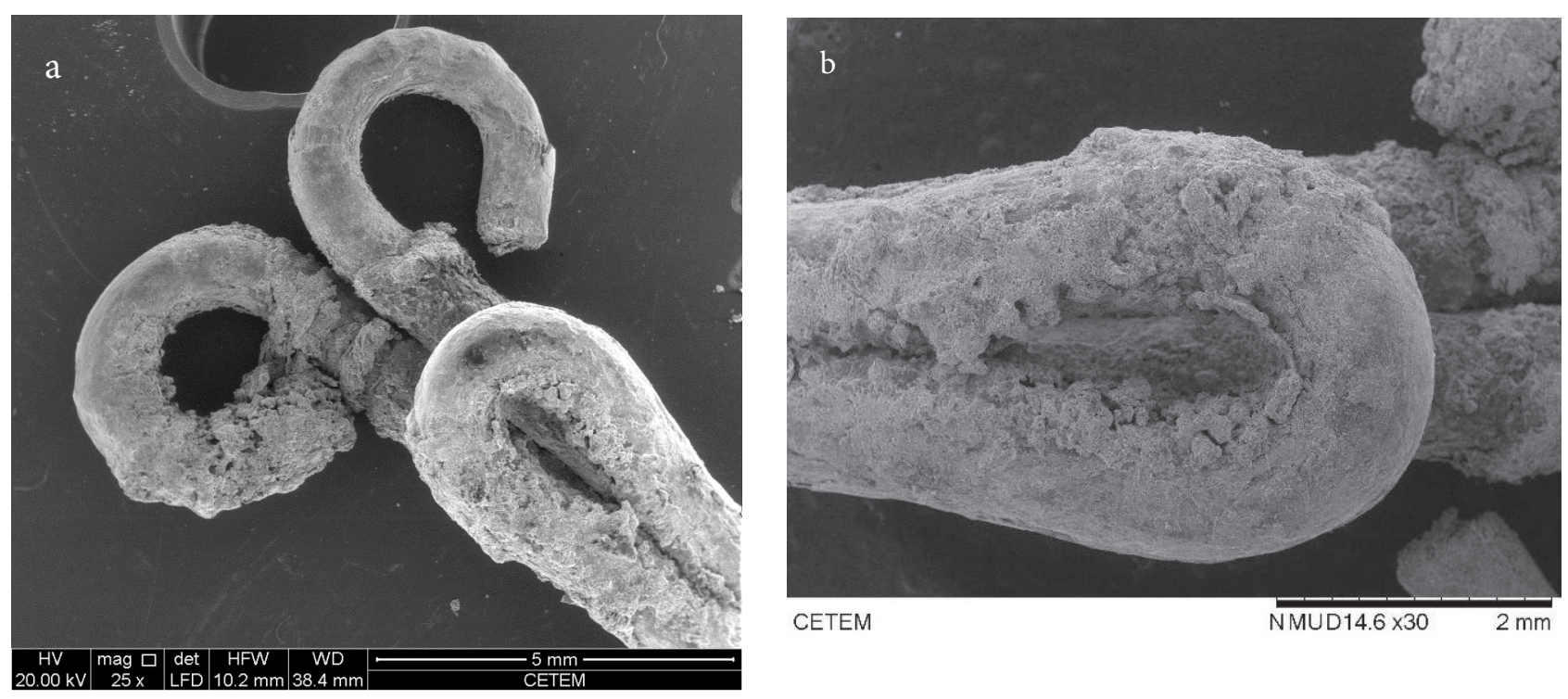

Figura 6 - Imagens obtidas ao MEV em elétrons secundários da superfície do colchete

Percebe-se em detalhes a formação dos produtos de corrosão na superfície, em camadas de espessura variada, de aspecto poroso e superfície irregular. Como consequência, a morfologia original da peça foi modificada pelos processos de mineralização.

A Figura 7, a seguir, mostra uma micrografia eletrônica de varredura por elétrons retroespalhados do colchete (a) e espectro de EDS da região mais clara analisada, indicada pelo circulo em amarelo (b). 

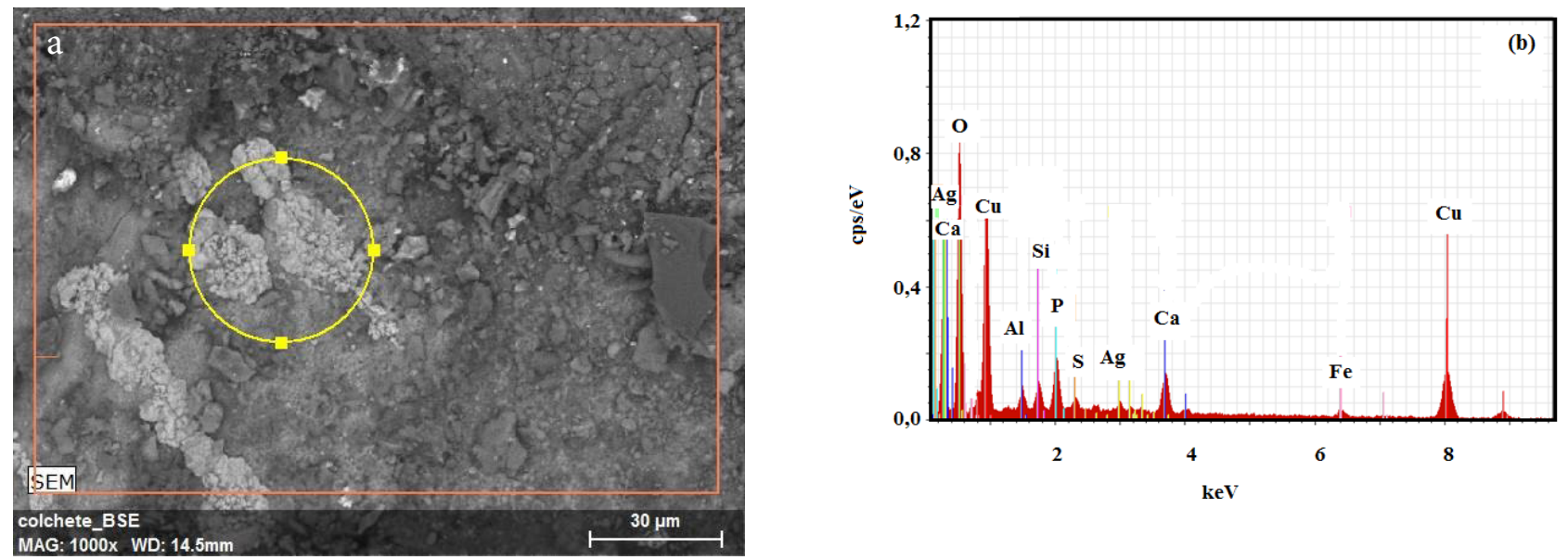

Figura 7 - MEV/EDS - a) Micrografia em elétrons retroespalhados da superfície do colchete, circulo amarelo indicando a região mais clara analisada por EDS; b) Espectro de EDS da região mais clara analisada, indicada pelo circulo em amarelo da Figura 7a

$\mathrm{Na}$ imagem (a) podem-se verificar diferenças de composição em áreas de colorações distintas. Nesse caso, foram efetuadas análises por EDS nas regiões mais claras, correspondentes à cor branca e cinza, como está assinalado em amarelo na Figura 7a. O espectro de EDS, apresentado na Figura 7b, revela os seguintes elementos: Ag, C, Ca, O, Fe, Cu, Al, Si, P e S. A presença de prata (Ag), em torno de $0,9 \% \mathrm{p} / \mathrm{p}$, mostrada na Figura $7 \mathrm{~b}$, sugere um possível recobrimento de prata (Ag) na superfície do colchete, na área indicada da Figura 7a, correspondendo às regiões mais claras. Dessa forma, destaca-se a importância da realização da caracterização do artefato antes da limpeza, ou a execução de uma limpeza mecânica leve, com o intuito de retirar o excesso de sedimento, a fim de evitar uma limpeza mais agressiva e o risco da retirada de constituintes importantes.

Nas análises realizadas nas regiões mais escuras que estão indicadas na Figura 8a (micrografia obtida com elétrons retroespalhados), não foi detectado o elemento Ag. Nessa região, foi realizado um mapeamento químico, como mostra a Figura 8 (b a g).

Nas Figuras 8c a 8g, pode-se observar a distribuição dos principais elementos químicos presentes na superfície da peça. O mapeamento indica que os elementos apresentam homogeneidade de distribuição entre si. A concentração de $\mathrm{Al}$ e $\mathrm{Si}$ provavelmente é decorrente de partículas do solo, enquanto que a presença de P possivelmente está relacionada com a proximidade da peça ao sepultamento.
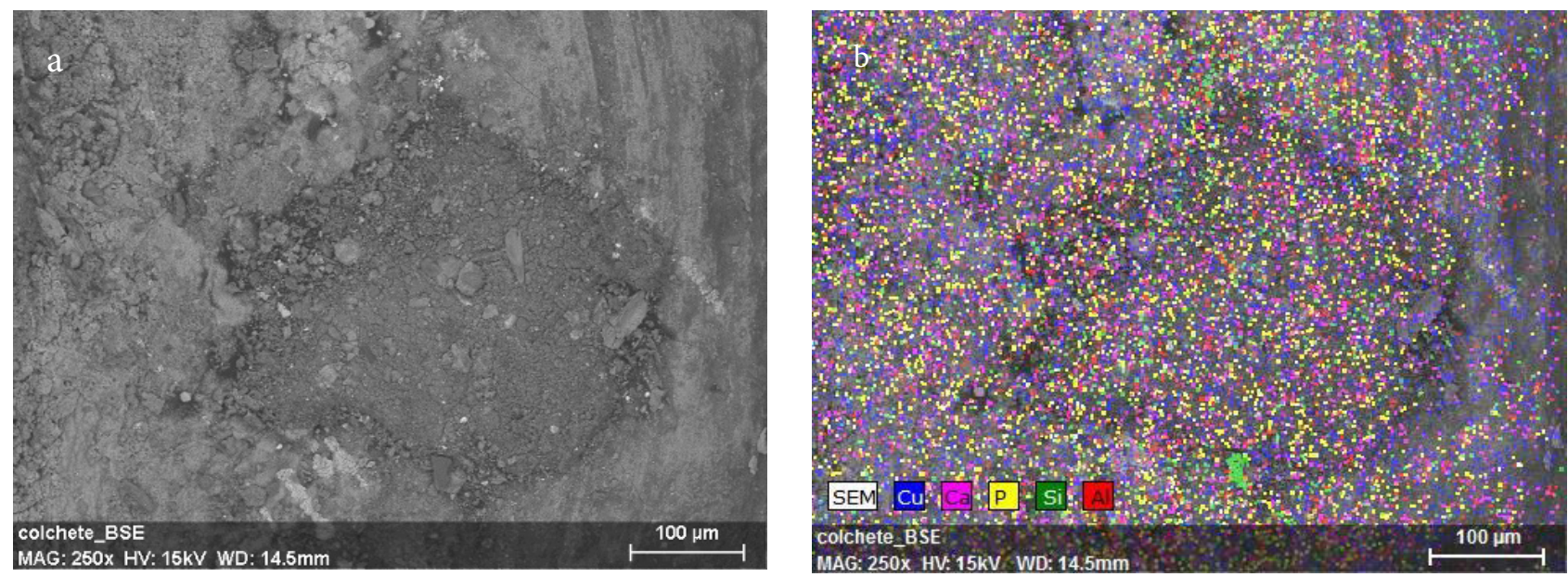

Figura 8a - MEV/ mapeamento - a) Micrografia em elétrons retroespalhados da região escura do colchete; b) Distribuição dos principais elementos $\mathrm{Ca}, \mathrm{Cu}, \mathrm{P}, \mathrm{Al}$ e Si utilizando o mapa de raios X; 

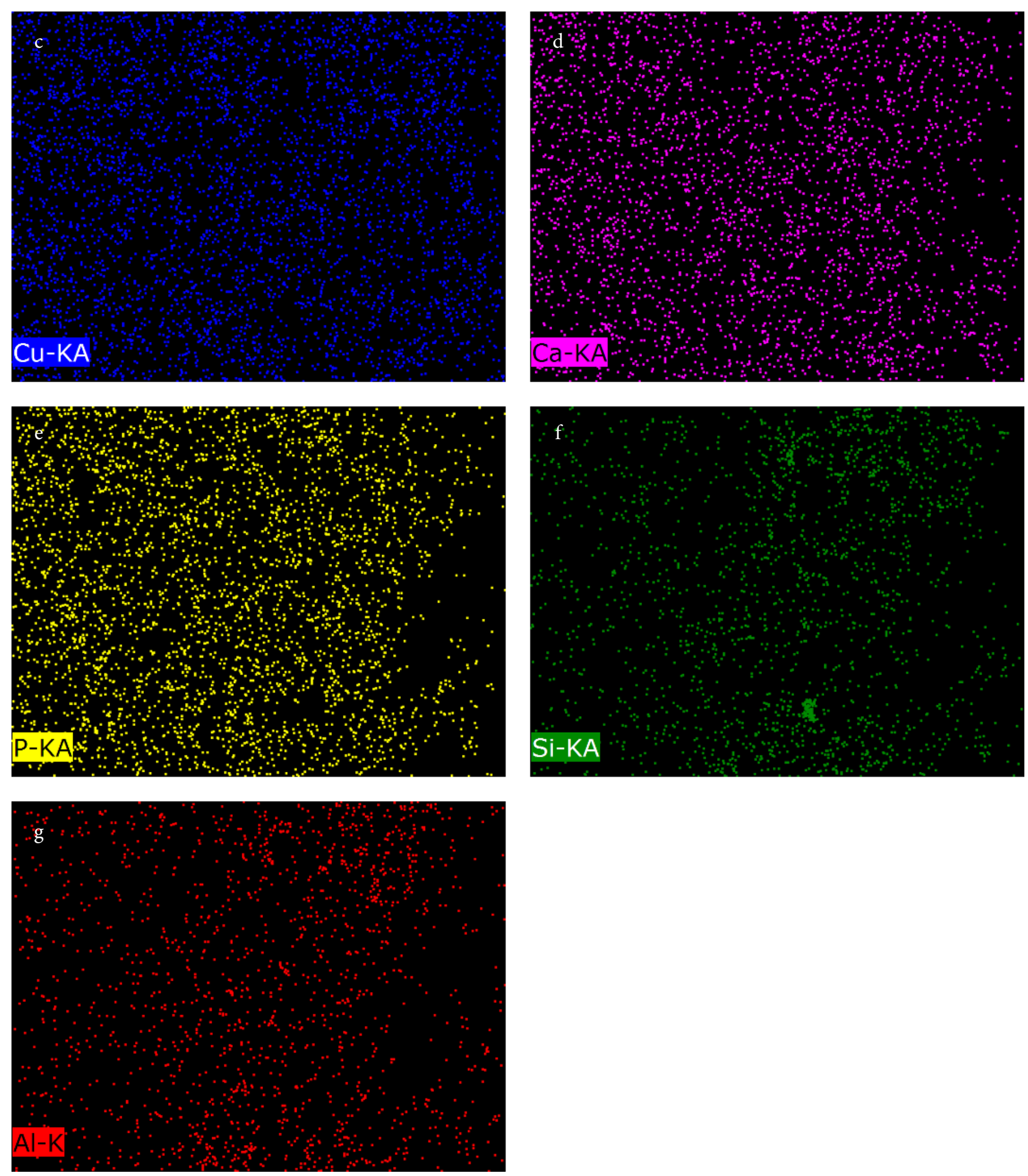

Figura 8b - MEV/ mapeamento c) azul, Cu; d) rosa, Ca; e) amarelo, P; f) verde, Si; g) vermelho, Al

Nas análises realizadas pelo DRX, foram observadas na superficie do colchete as seguintes fases: malaquita, cobre, cuprita e nantoquita, mostradas no difratograma que corresponde à Figura 9, a seguir. 


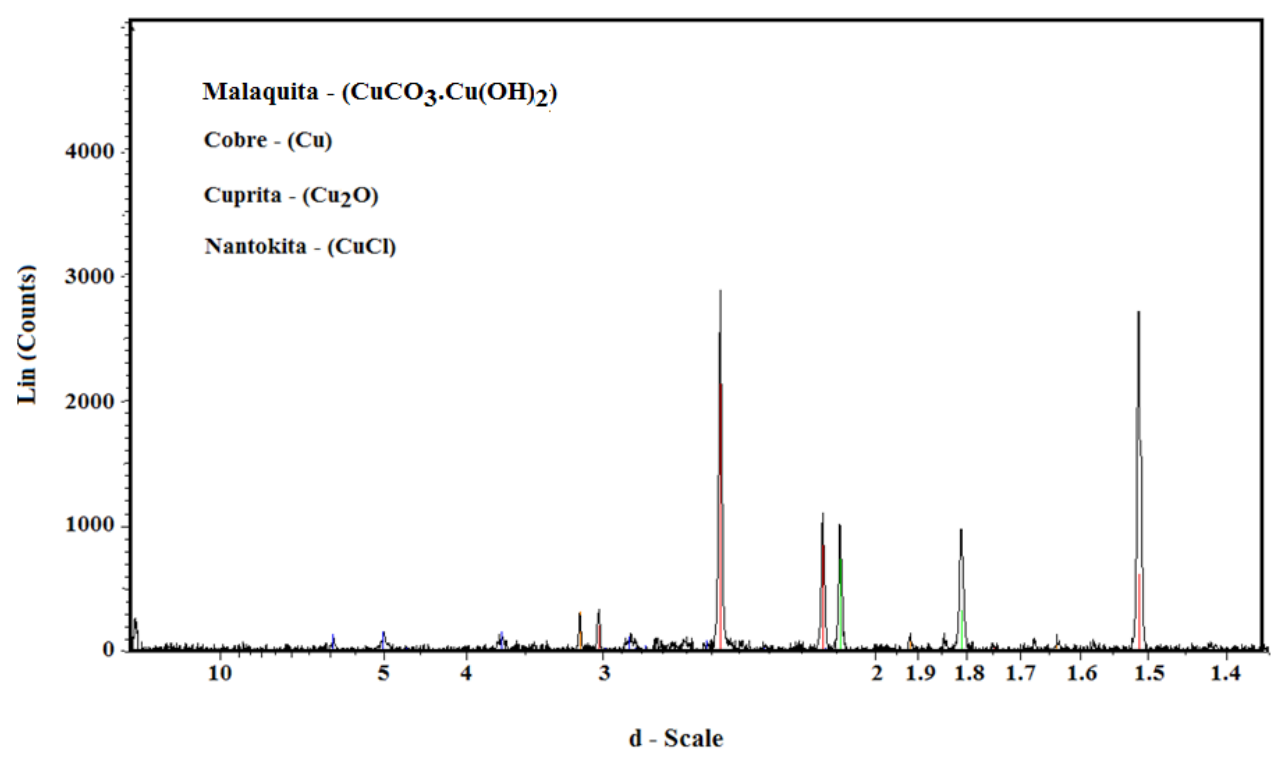

Figura 9 - Difratograma $(\mathrm{Cu} \mathrm{K} \square)$ referente ao colchete. Foram identificadas as seguintes fases: cobre, cuprita, malaquita e nantoquita

Os resultados indicam que parte das informações obtidas no exame visual correspondem ao resultado experimental, o qual mostra que a região de coloração avermelhada condiz com a presença de cuprita $\left(\mathrm{Cu}_{2} \mathrm{O}\right)$. A Cuprita é o primeiro composto a ser formado sobre o metal, de caráter protetivo, é considerada uma pátina nobre.

A malaquita $\left(\mathrm{CuCO}_{3} \cdot \mathrm{Cu}(\mathrm{OH})_{2}\right)$ é um carbonato básico de cobre, de coloração verde pálido. Trata-se de um composto muito associado aos artefatos arqueológicos, desenvolvido no período em que permaneceram em contato com o solo. A malaquita geralmente se constitui acima da camada inicial de cuprita. É uma pátina com um processo de formação lento, indica a autenticidade do artefato, pela dificuldade em desenvolver em laboratório a transição da cuprita para a malaquita (SCOTT, 2002).

A nantoquita $(\mathrm{CuCl})$ é um cloreto instável com a presença de umidade e oxigênio (LAGO, 2005). De coloração cinza claro, tem aspecto pulverulento. Associada à corrosão ativa do material quando instável, pode originar a formação de pontos verdes na superfície do material, expandindo-se e aumentando de volume (SCOTT, 2002). Essas alterações são conhecidas como "doença do bronze", que indicam uma acumulação de depósitos de cloretos, sugerindo uma instabilidade que pode penetrar na parte interna do artefato (HOBBS, 2002) impossibilitando a sua retirada por meios mecânicos, causando perdas de material.

Adicionalmente, com base no resultado, a análise de DRX do colchete revelou que o cobre era um dos principais componentes da peça. Dessa forma, o DRX mostrou-se uma técnica adequada para caracterizar as fases presentes na peça analisada.

\section{Crucifixo}

Através do primeiro exame visual, no microscópio estereoscópico, foi possível verificar, como mostra a Figura 10, distintas camadas sobrepostas, de diferentes produtos de corrosão. Observa-se uma variedade de colorações, o verde claro, verde escuro e regiões avermelhadas, assim como constituições morfológicas distintas, variando de grumosas a plaqueiformes, em camadas de profundidades desiguais. 


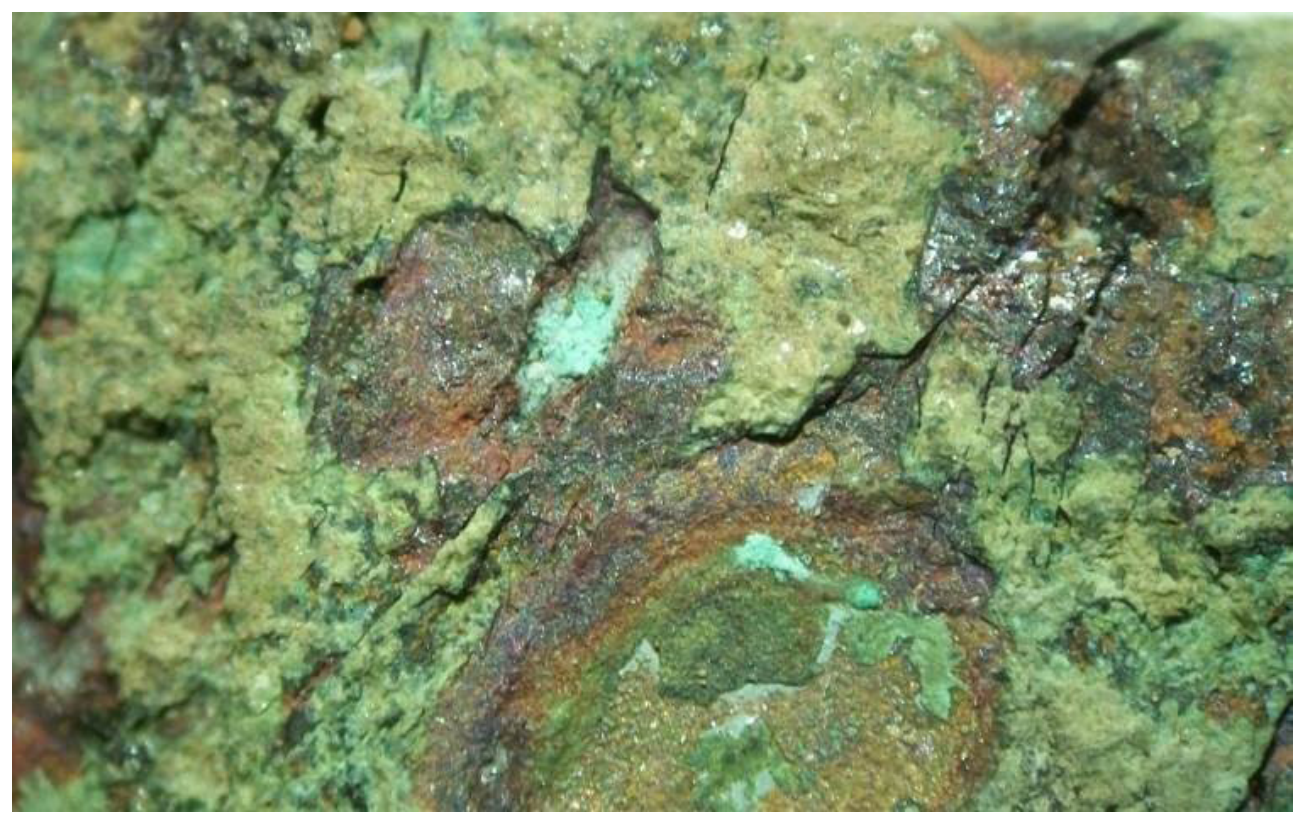

Figura 10 - Imagem obtida através do microscópio estereoscópico de área do crucifixo, mostrando produtos de corrosão de diferentes colorações

A Figura 11, a seguir, apresenta a imagem radiográfica do artefato.

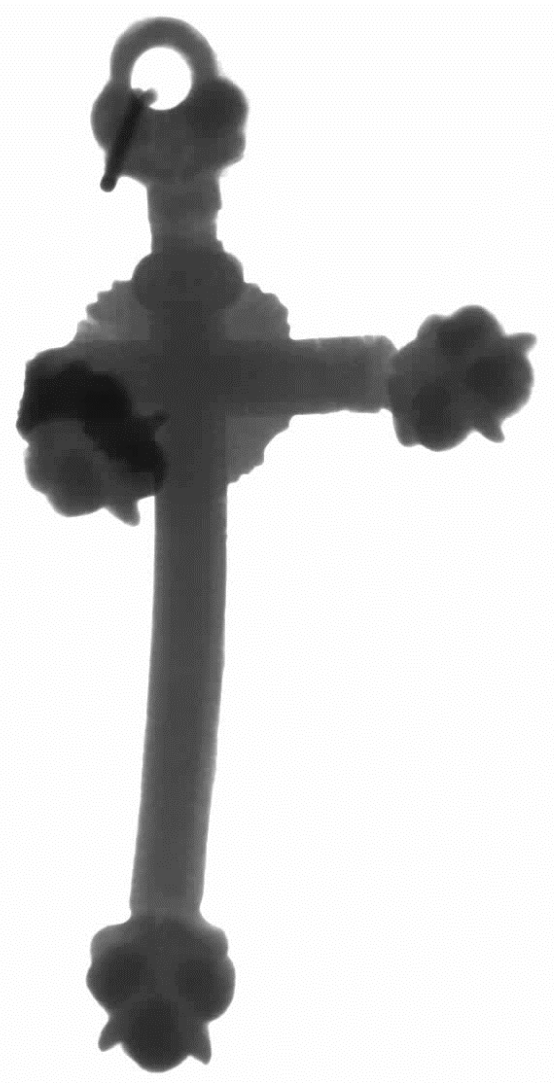

Figura 11 - Imagem de uma radiografia positiva do crucifixo, mostrando a estrutura da peça e suas diversas partes constituintes

Verifica-se que a cruz do crucifixo, de linhas direitas (cruz latina: braço vertical maior do que o horizontal) apresenta os arremates dos braços em forma de ponteiras trabalhadas, e na face posterior do cruzamento dos braços observa-se um res- 
plendor radiado. Na parte superior do crucifixo, é possível visualizar uma argola, presa à ponteira que apresenta uma abertura circular utilizada para pendurar o crucifixo em um colar.

Em relação à intensidade de escurecimento na imagem, verifica-se que existe alma metálica nos braços da cruz, mostrando que nem toda a parte metálica foi mineralizada. As ponteiras aparentam terem sido fixadas nos extremos dos braços através de soldagem, já que se percebe uma fase mais clara, representando uma liga metálica menos densa, entre o corpo dos braços e as ponteiras propriamente ditas. Isso é mais perceptível no encontro da ponteira superior com o corpo da cruz, indicando provavelmente que o cordão de solda ali existente é maior, para suportar as tensões mecânicas nesse local.

A existência de fase metálica do material original de constituição do artefato é representada por toda a área mais escura na imagem, especialmente nos braços. O resplendor radiado também apresenta coloração mais clara que o corpo da cruz, mostrando que foi aplicado após o cruzamento dos braços e deve ser constituído de metal ou liga menos densa.

A Figura 12, a seguir, mostra imagens microtomográficas do artefato, onde podem ser verificados detalhes de elementos de fabricação e decoração, sem sobreposição, não visíveis pela radiografia. Essa técnica, ao contrário da anterior, possibilita visualizar em 3D uma face do artefato sem intereferência da outra face.
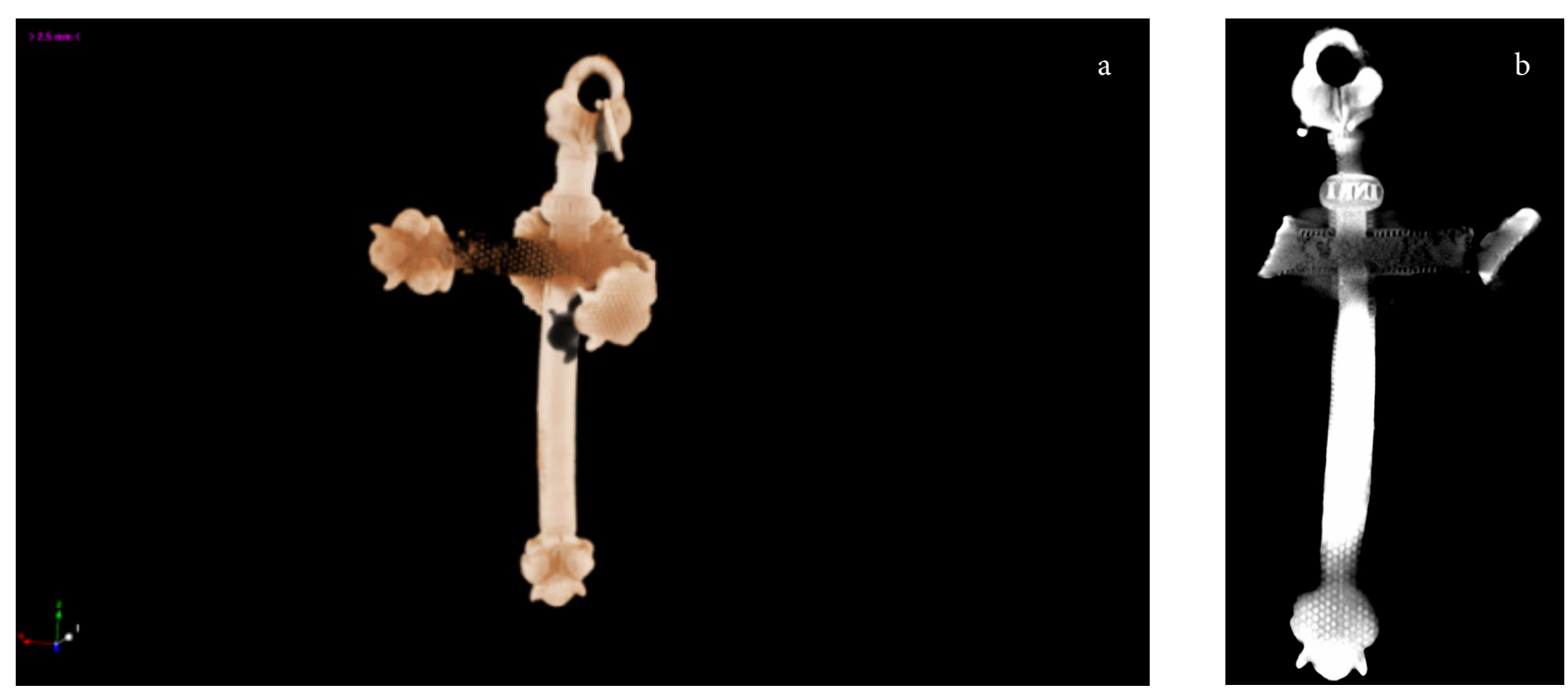

Figura 12 - Imagens microtomográficas do crucifixo obtida por MicroCT; a) anverso; b) reverso.

É possível visualizar detalhes decorativos nos braços, similares a um pontilhado e, também, o braço direito envergado para dentro, provavelmente devido à ação mecânica. A inscrição INRI está visível um pouco acima do cruzamento dos braços, sendo um acrônimo da frase em latim Iēsus Nazarēnus, Rēx Iūdaeōrum, cuja tradução é “Jesus Nazareno (ou, de Nazaré), Rei dos Judeus", típica das cruzes religiosas cristãs. A argola está aparentemente preservada em sua morfologia e verifica-se que suas pontas não se encontram unidas, e sim defasadas e em paralelo.

As micrografias capturadas pelo MEV/EDS, observadas na Figura 13, são, respectivamente, imagens em elétrons secundários (a) e retroespalhados (b) de diferentes regiões da ponteira e braço do crucifixo.

As micrografias da Figura 13 permitem comparar informações relacionadas à composição e à morfologia/topografia do mesmo local do crucifixo (ponteira esquerda). A Figura 13a apresenta camada bem espessa de produto de corrosão, de superfície muito rugosa, estratificação e profundidades irregulares. Verifica-se que a ponteira é mais volumosa que a barra do braço do crucifixo, que apresenta aparência próxima à morfologia e constituição original, principalmente no reverso. Podese observar, também, pequenas áreas de coloração mais clara que, na Figura 13b em elétrons retroespalhados, referem-se a 
contraste composicional acentuado. Nesta imagem (b) foi realizada microanálise por EDS, na parte escura, que corresponde ao restante do braço, e na região mais clara, respectivamente indicadas pelos números 1 e 2 .

Os resultados de EDS obtidos para as posições (1 e 2), apontadas na Figura 13b, podem ser observados na Figura 14 (a e b).
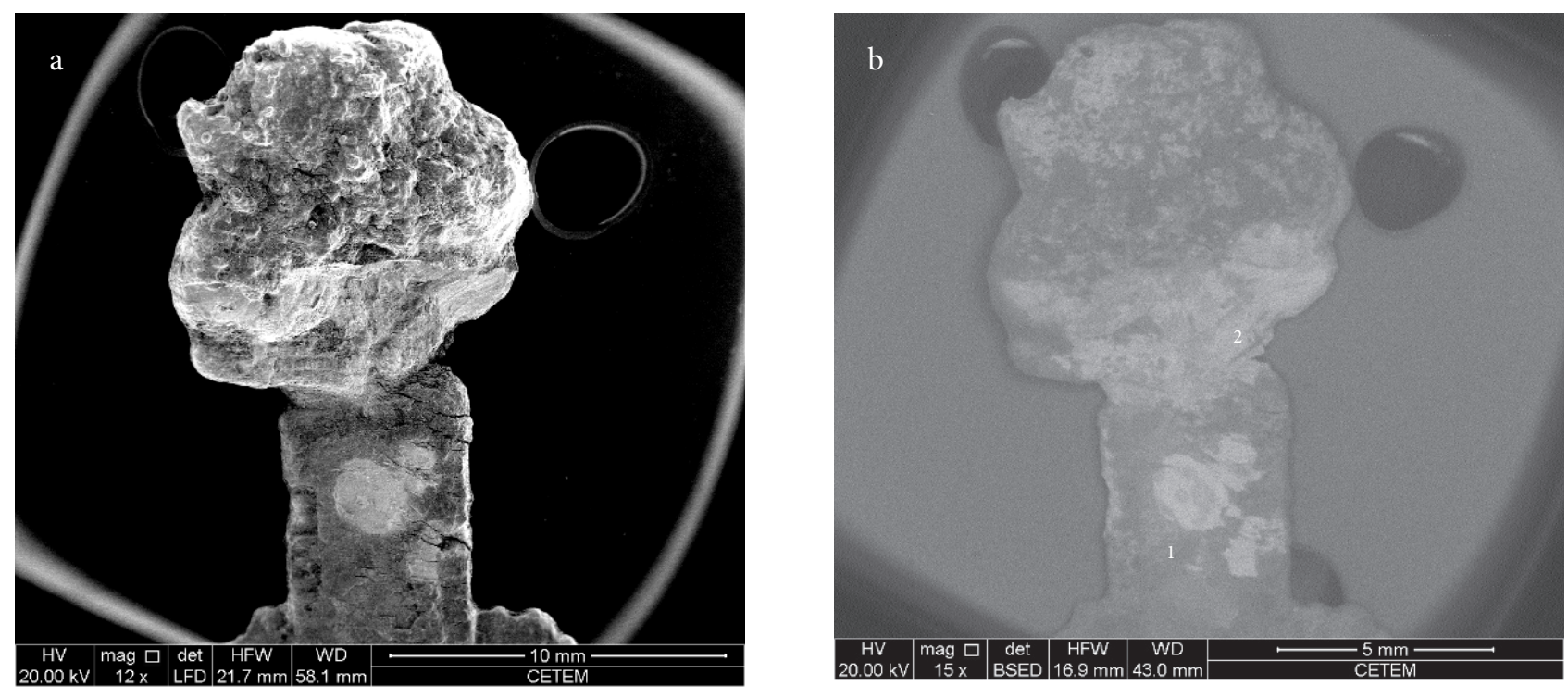

Figura 13 - Imagem obtida ao MEV para o braço/ponteira esquerda do crucifixo. a) em elétrons secundários; b) em elétrons retroespalhados
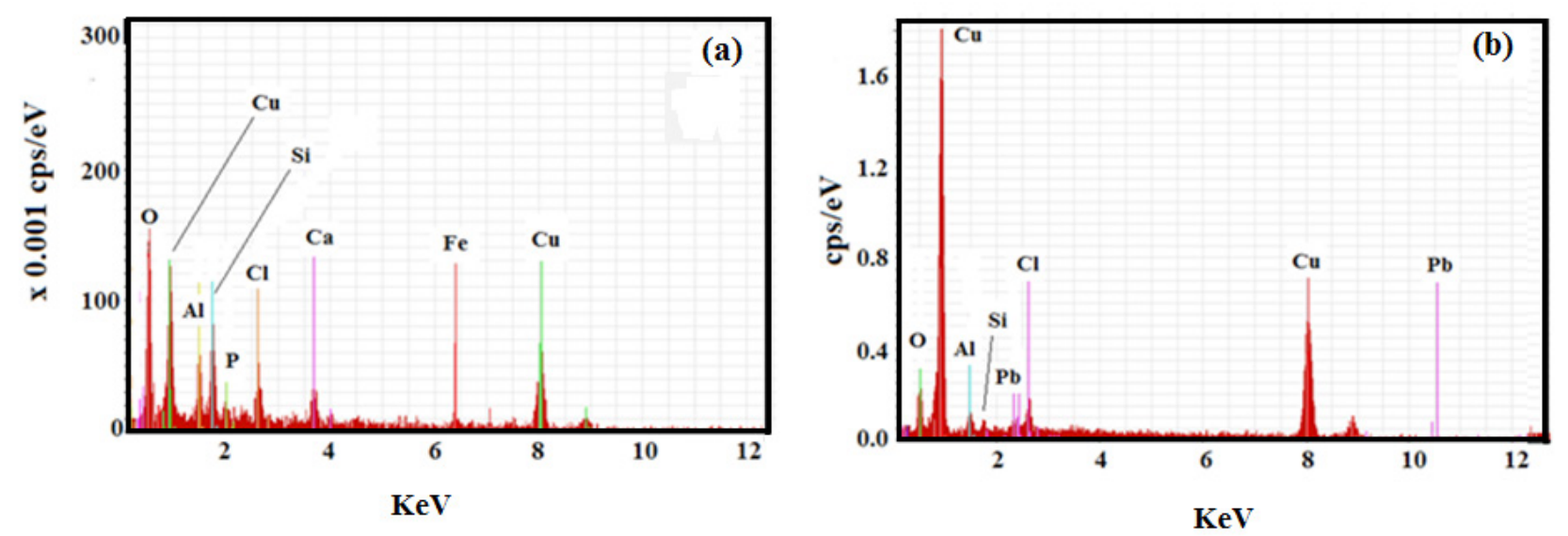

Figura 14- Espectros de EDS do crucifixo do braço/ponteira esquerda referente a Figura 6b: (a) ponto 1; (b) ponto 2.

O espectro referente ao braço horizontal (Figura 14a) acusa a presença do Cu, Si, Fe, P, O, Al, Cl e Ca. Na Figura 14b, observa-se o espectro correspondente à área mais clara e revela os elementos $\mathrm{Cu}, \mathrm{Si}, \mathrm{O}, \mathrm{Al}, \mathrm{Pb}$ e $\mathrm{Cl}$. O artefato provavelmente é constituído de cobre, com presença de precipitados de chumbo, que determina a cor mais clara na Figura 14b (ponto 2). Na micrografia em elétrons retroespalhados, mostrada na Figura 13b, observa-se apenas uma parte visível da inscrição INRI, pois, algumas áreas estão mineralizadas, resultando na perda de informação visual.

A Figura 15, a seguir, mostra o cruzamento dos braços do crucifixo, o resplendor em nível posterior, um trabalho decorativo nas bordas dos braços e no braço direito que está envergado. 
Os resultados de EDS obtidos para as posições (1, 2 e 3), apontadas na Figura 15, podem ser observados na Figura $16(a, b$ e c).

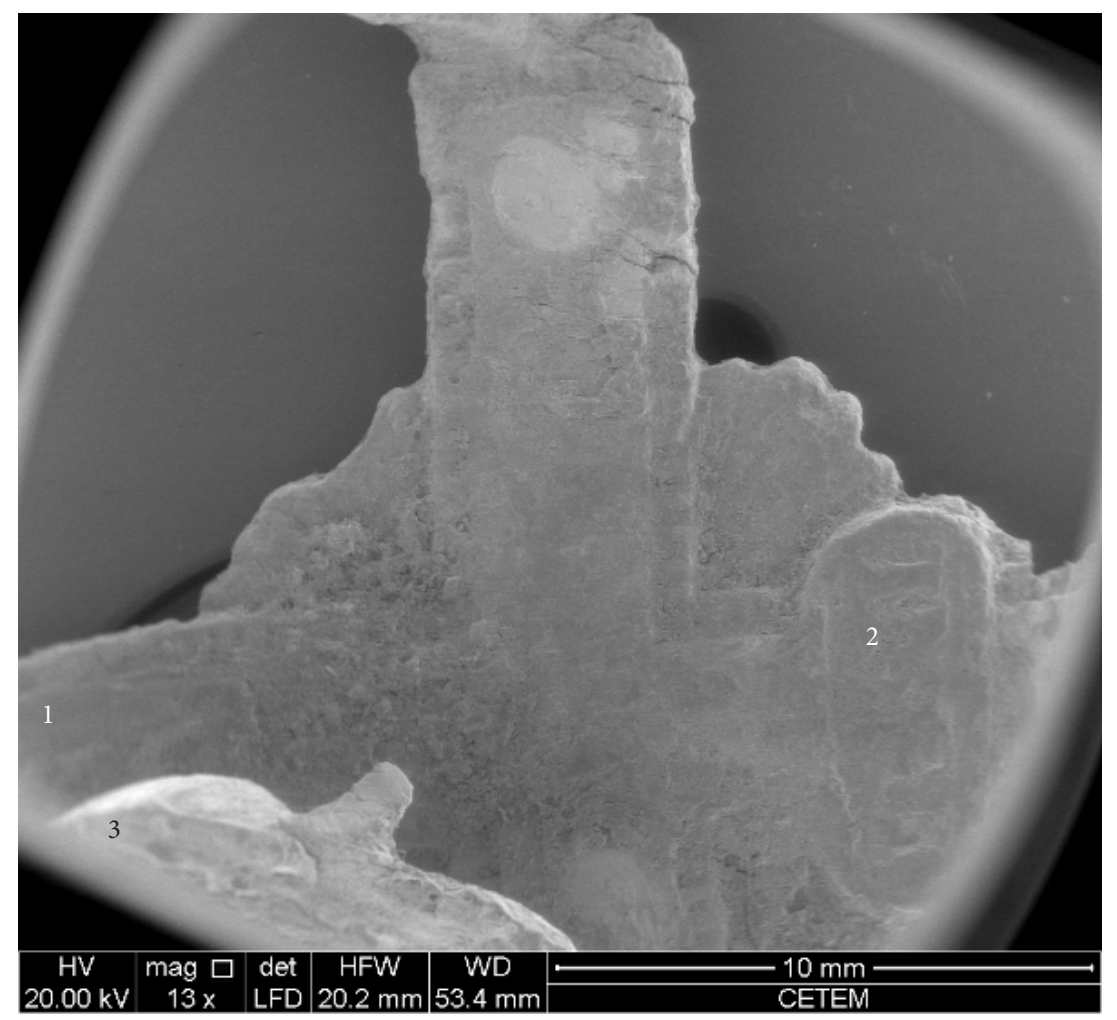

Figura 15 - Imagem obtida ao MEV em elétrons retroespalhados do crucifixo
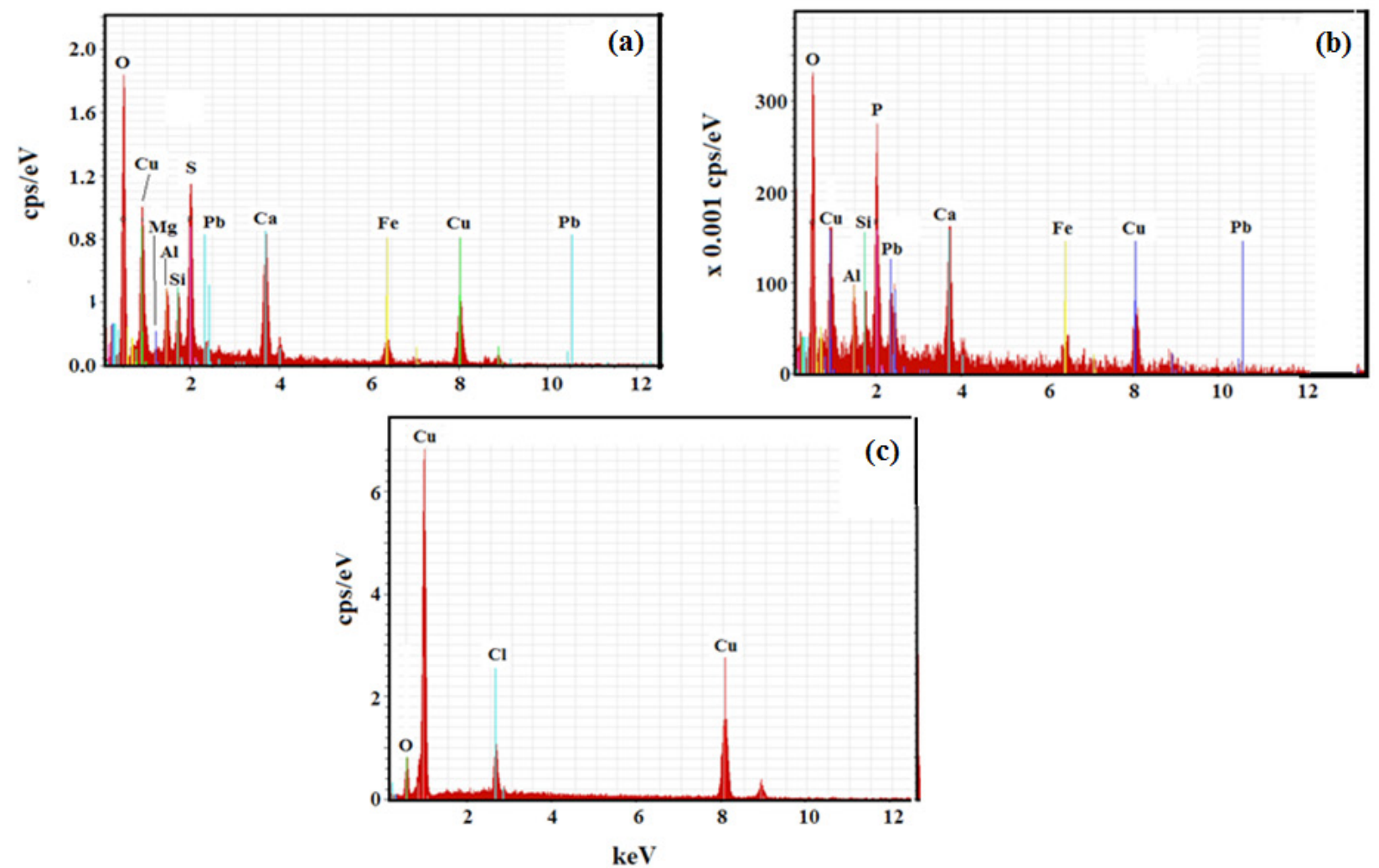

Figura 16 - Espectros de EDS do crucifixo dos pontos indicados na Figura 15: (a) ponto 1; (b) ponto 2; (c) ponto 3 
$\mathrm{O}$ espectro referente ao braço vertical (Figura 15, ponto 1) acusa a presença do $\mathrm{Cu}, \mathrm{Si}, \mathrm{Fe}, \mathrm{O}, \mathrm{Al}, \mathrm{Mg}, \mathrm{S}, \mathrm{Pb}$ e $\mathrm{Ca}$ (Figura 16a). Na Figura 16b, observa-se o espectro correspondente à área da inscrição INRI (Figura 15, ponto 2) e revela os elementos $\mathrm{Cu}, \mathrm{Si}, \mathrm{Fe}, \mathrm{P}, \mathrm{O}, \mathrm{Al}, \mathrm{Pb}$ e Ca. A Figura 16c apresenta o espectro referente à região mais clara do braço horizontal envergado (Figura 15, ponto 3) e aponta os elementos $\mathrm{Cu}, \mathrm{O}$ e Cl. A diferença de composição entre os pontos 1 e 2 (existência de $\mathrm{Mg}$ e S no ponto 1) permite inferir que os produtos de corrosão possuem composição mais complexa neste ponto. Os produtos de corrosão no ponto 3 apresentam composição bem mais simples que nos demais e a presença de $\mathrm{Cl}$ (Figura 16c) indica possivelmente a existência de um cloreto nesta área.

A microanálise por EDS identificou, nos diferentes espectros, o empobrecimento do cobre em algumas regiões da peça, possivelmente decorrente do processo de decuprificação. A presença de S no crucifixo provavelmente indica que esteja relacionada com inclusões de sulfeto de cobre, que pode ser proveniente da origem da obtenção do metal.

A análise por difratometria de raios $\mathrm{X}$ foi realizada em um fragmento do produto de corrosão que se desprendeu da superfície do crucifixo. O difratograma dessa análise é apresentado na Figura 17, a seguir.

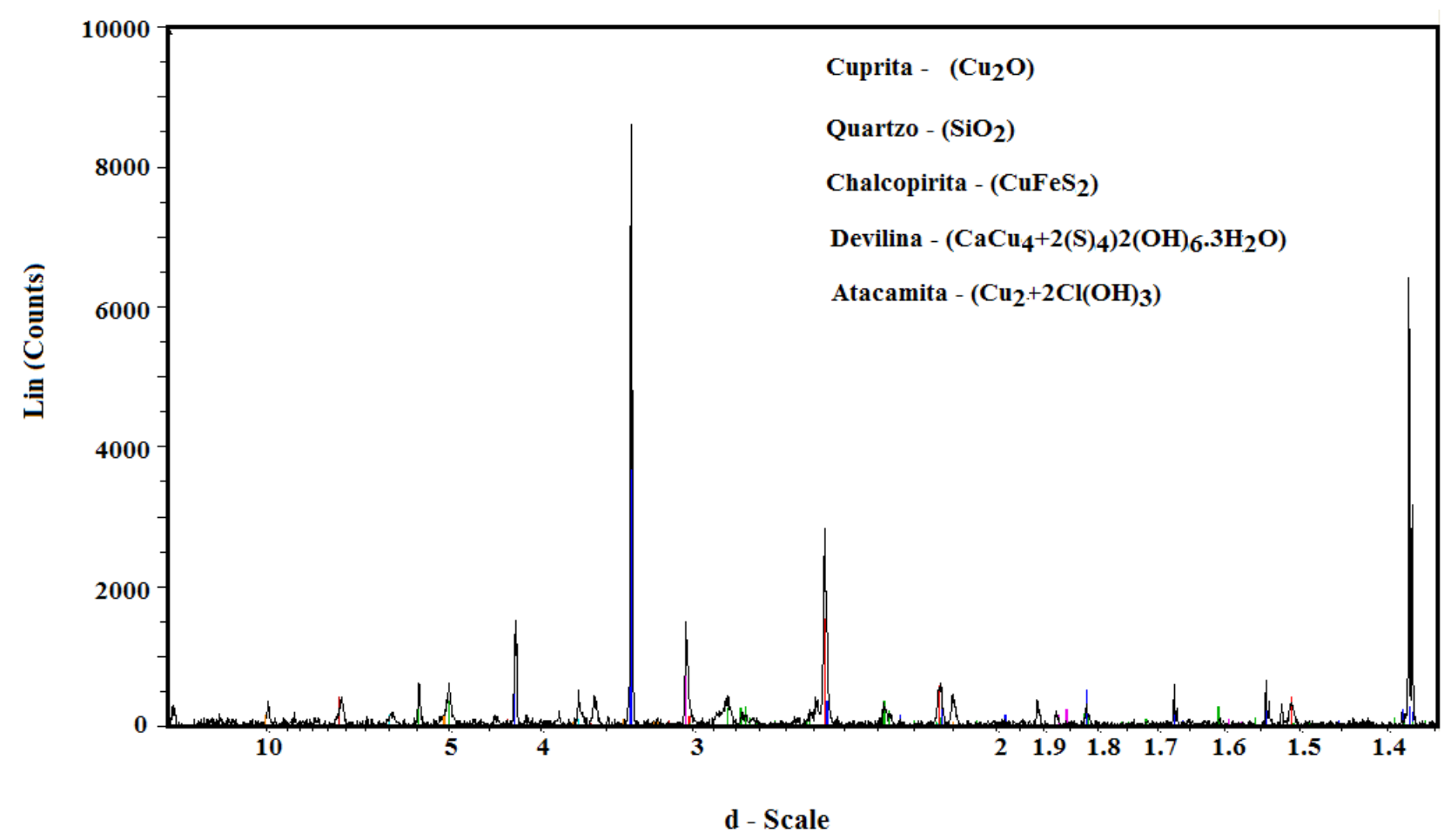

Figura 17 - Difratograma $(\mathrm{Cu} \mathrm{K} \alpha)$ referente aos produtos de corrosão do Crucifixo. Foram identificadas as seguintes fases: cuprita, sílica/quartzo, chalcopirita, devilina e atacamita

Cinco fases minerais foram obtidas, evidenciando que a presença de cobre é bem siginificativa, deduzindo que o material que constitui o crucifixo é cobre. O quartzo, uma das formas naturais da sílica $\left(\mathrm{SiO}_{2}\right)$, está provavelmente relacionado com partículas do solo, como grãos de areia. A cuprita $\left(\mathrm{Cu}_{2} \mathrm{O}\right)$ é um óxido de cobre e o primeiro produto de corrosão a ser formado sobre o cobre e suas ligas. Trata-se de um composto estável e aderente à superfície da peça. A cuprita corresponde à região de coloração avermelhada, visualizada anteriormente no microscópio estereoscópico.

A atacamita $\left(\mathrm{Cu}_{2}(\mathrm{OH})_{3} \mathrm{Cl}\right)$ é um cloreto básico de cobre, de coloração verde, não é o primeiro composto a se formar na superfície do metal (SCOTT, 2002). Esse cloreto, misturado com outros compostos estáveis, como a cuprita, não representa grandes riscos ao artefato (LAGO, 2005). A existência de um cloreto de cobre nas pátinas, não indica necessariamente a pre- 
sença do fenômeno vulgarmente conhecido como "doença do bronze", mas pode sugerir um processo de corrosão localizado ou superficial (SCOTT, 2002).

A devilina $\left(\mathrm{CaCu} 4(\mathrm{SO} 4)_{2}(\mathrm{OH})_{6} .3 \mathrm{H} 2 \mathrm{O}\right)$ é um sulfato de coloração cinza azulado e a calcopirita $\left(\mathrm{CuFeS}_{2}\right)$ é um sulfeto de cor amarelo avermelhado. Conforme foi detectado no EDS, é provável que a presença de S esteja relacionada com inclusões de sulfeto de cobre, indicando a origem da obtenção do metal.

\section{Botão}

$\mathrm{Na}$ análise macroscópica do botão, através do microscópio estereoscópico, podem-se observar na superfície do artefato diferentes tonalidades de produtos de corrosão, como a coloração verde claro, verde escuro e regiões avermelhadas, como mostra a Figura 18.

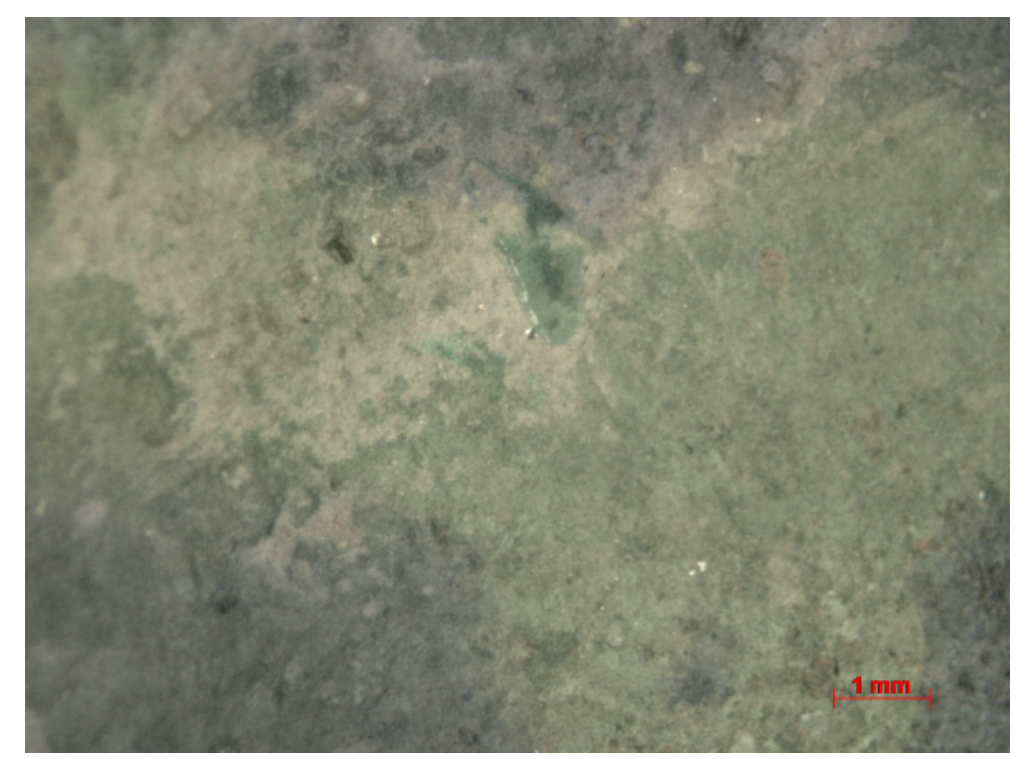

Figura 18 - Imagem obtida através do microscópio estereoscópico do botão, mostrando produtos de corrosão de diferentes colorações como verde claro e escuro e regiões avermelhadas

Através da imagem radiográfica, mostrada na Figura 19, foi possível visualizar os detalhes tecnológicos e as partes constituintes do artefato.

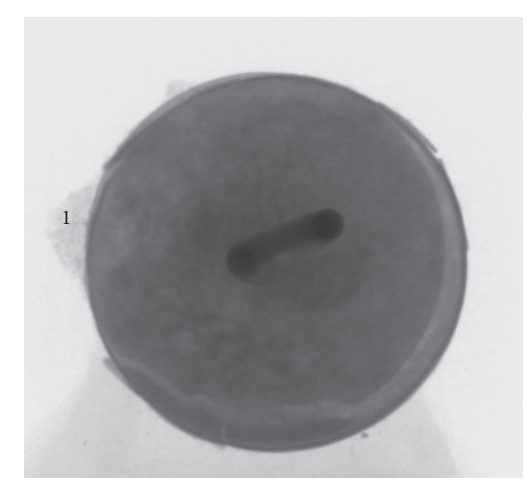

Figura 19 - Imagem de uma radiografia positiva do botão, mostrando a estrutura da peça e suas partes constituintes. O Ponto 1 indica a região mineralizada, de menor densidade. 
Verificou-se que a montagem do botão de formato arredondado é constituída de duas partes que se encaixam, uma côncava e outra reta, e um pé arredondado, utilizado para a costura na roupa. Também foi possível visualizar a extensão das regiões mineralizadas (mais claras - ponto 1) e algumas fissuras nas bordas.

Imagens em 3D geradas pelo programa CTvox do botão são mostradas na Figura 20 (a e b).
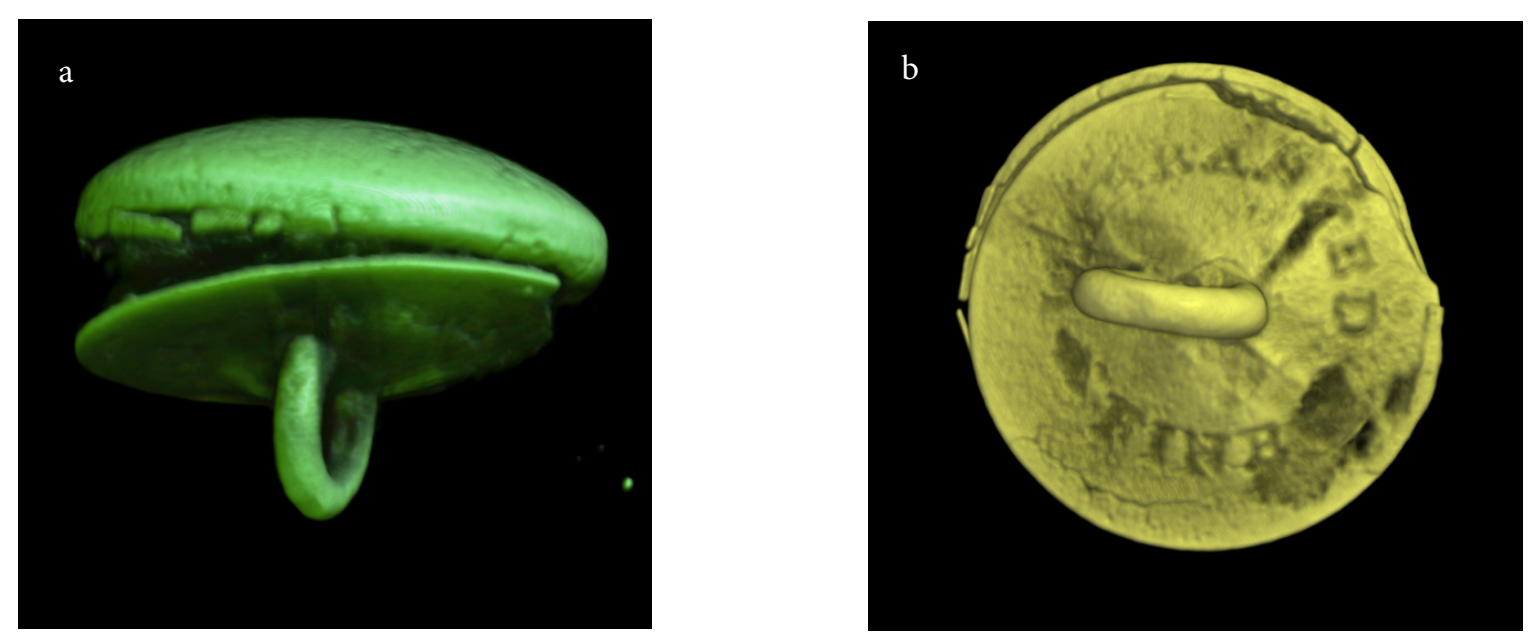

Figura 20 - Imagens em 3D geradas pelo programa CTvox de um botão de cobre, (a) em vista lateral e (b) de frente, lado plano.

Pela MicroCT, pode-se obter uma melhor visualização em 3D do artefato, mostrando o desencontro das duas partes deslocadas que constituem o botão, as fissuras e as rachaduras nas bordas. Observa-se também, com mais detalhes, o formato do pé arredondado para a costura. No lado plano do botão, é possível visualizar uma parte da inscrição, que não é visível a olho nu, coberta pelos produtos de corrosão, com letras como F, I, N, B ....W ... B, D. A inscrição, provavelmente, está relacionada à marca do fabricante, de possível procedência inglesa.

A morfologia do lado plano do botão, na região interna da parte concava , pode ser identificada por MEV, mostrada na Figura 21, a seguir.

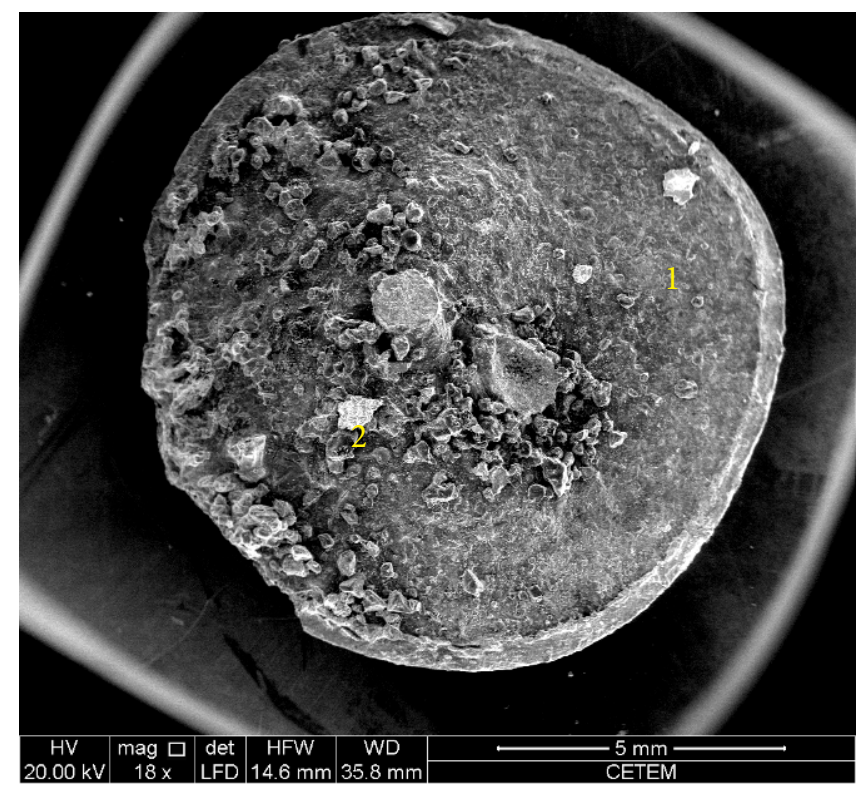

Figura 21 - Imagem em elétrons secundários obtida por MEV para o botão. Os pontos 1 e 2 indicam as regiões em que foram realizadas as microanálises por EDS 
Podem-se notar irregularidades na superficie e uma área clara destacada do metal, que corresponde a um material branco que se encontra na junção das duas faces do botão.

A Figura 21 mostra regiões em que foram realizadas as microanálises por EDS, a matriz e a área mais clara. Essas áreas são respectivamente indicadas pelos números 1 e 2. O espectro EDS, obtido da superfície na área identificada com o número 1, na Figura 21, é apresentado na Figura 22a, enquanto que o espectro correspondente à região mais clara no ponto 2 corresponde à Figura 22b.
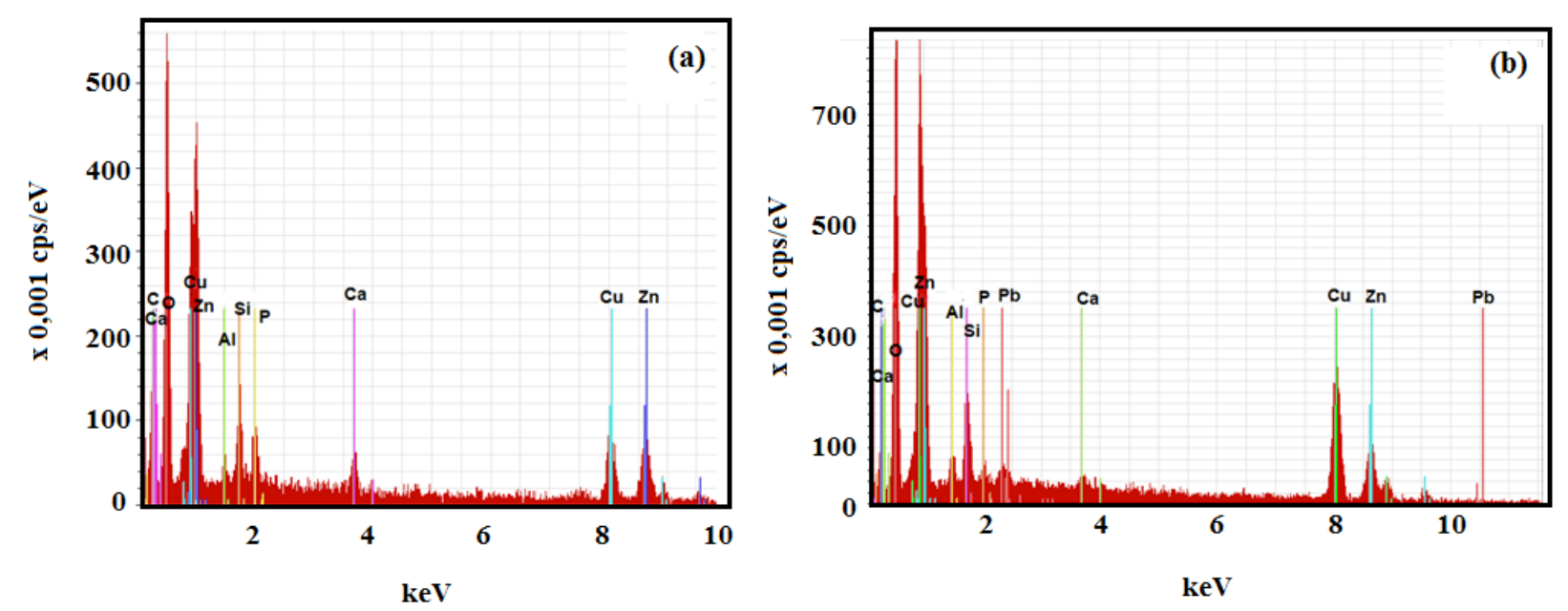

Figura 22 - Espectros de EDS referentes ao Botão: a) Ponto 1; b) Ponto 2.

Na Figura 22, observa-se que o $\mathrm{Cu}$ aparece com intensidades diferentes nos dois espectros a e b. Em ambos os espectros foram detectados os elementos $\mathrm{Cu}, \mathrm{Zn}, \mathrm{C}, \mathrm{Ca}, \mathrm{Al}, \mathrm{Si}, \mathrm{P}$ e O, enquanto apenas na região mais clara foi detectado o $\mathrm{Pb}$. O material metálico original utilizado possivelmente se trata de uma liga de cobre e zinco, um latão, com um pequeno percentual de chumbo, geralmente adicionado para melhorar a conformabilidade dessa liga (SMITH, 1999). Provavelmente a presença de $\mathrm{Al}$ e Si é decorrente de partículas do solo e o P está relacionado com a proximidade da peça ao enterramento.

O difratograma da superfície da parte branca do material (Figura 2c), mostrado na Figura 23, detectou as seguintes fases: gerardita $\left(\mathrm{Cu}_{2}(\mathrm{OH})_{3} \mathrm{NO}_{3}\right)$, de coloração verde transparente, e a esteatita $\left(\mathrm{Mg}_{3} \mathrm{Si}_{4} \mathrm{O}_{10}(\mathrm{OH})_{2}\right)$, de coloração branca, que corresponde ao talco.

Provavelmente o talco foi utilizado como recheio do botão constituído de uma estrutura metálica. O produto de corrosão identificado (gerardita), que contaminou o recheio de talco, mostra a presença de compostos de nitrogênio no solo que reagiram com as partes metálicas do botão.

A Figura 24, a seguir, apresenta o difratograma de raios-X da superfície do botão. 


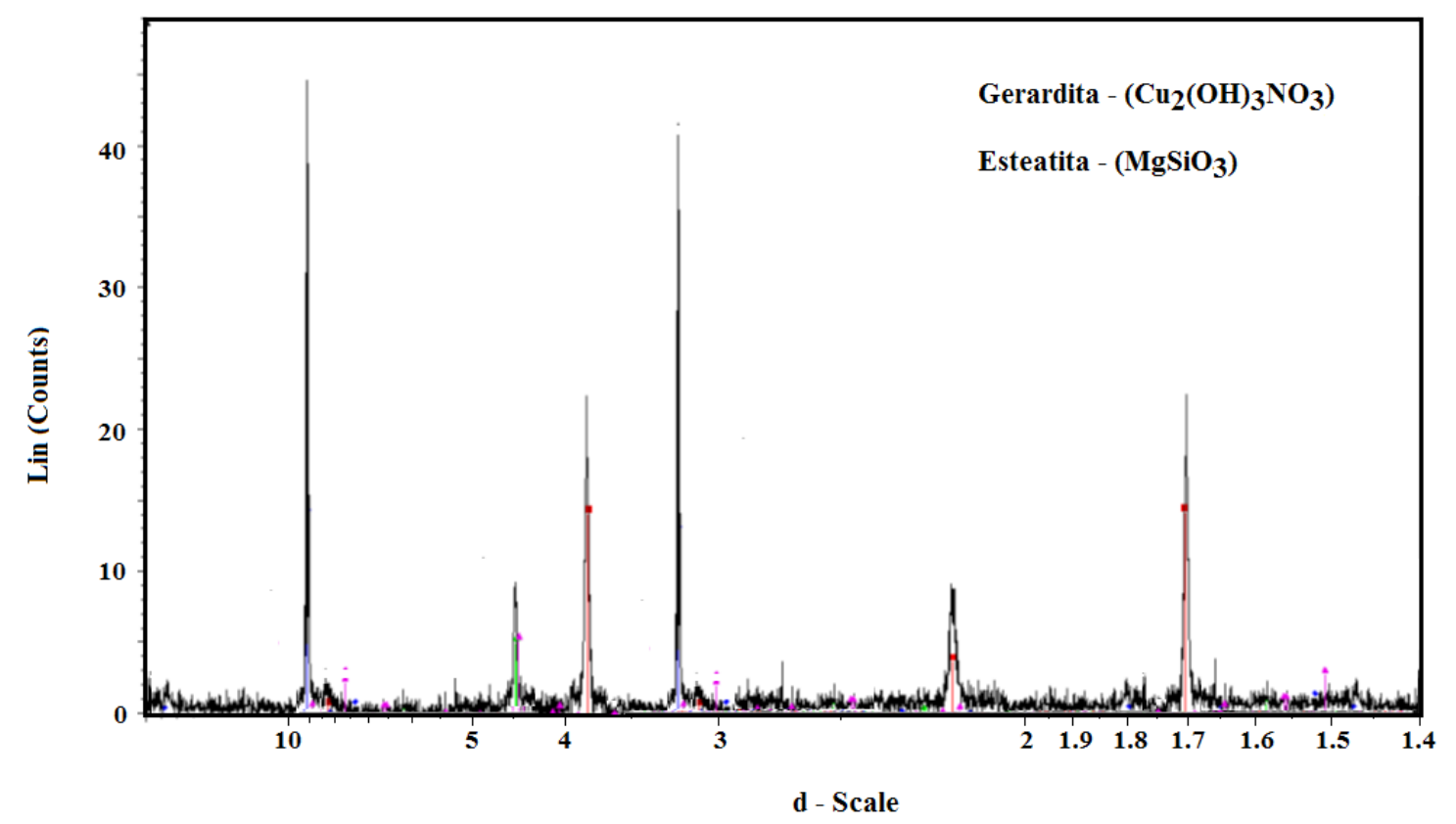

Figura 23 - Difratograma $(\mathrm{Cu} \mathrm{K} \alpha)$ referente à região branca do Botão. Foram identificadas as fases Gerardita e a Esteatita

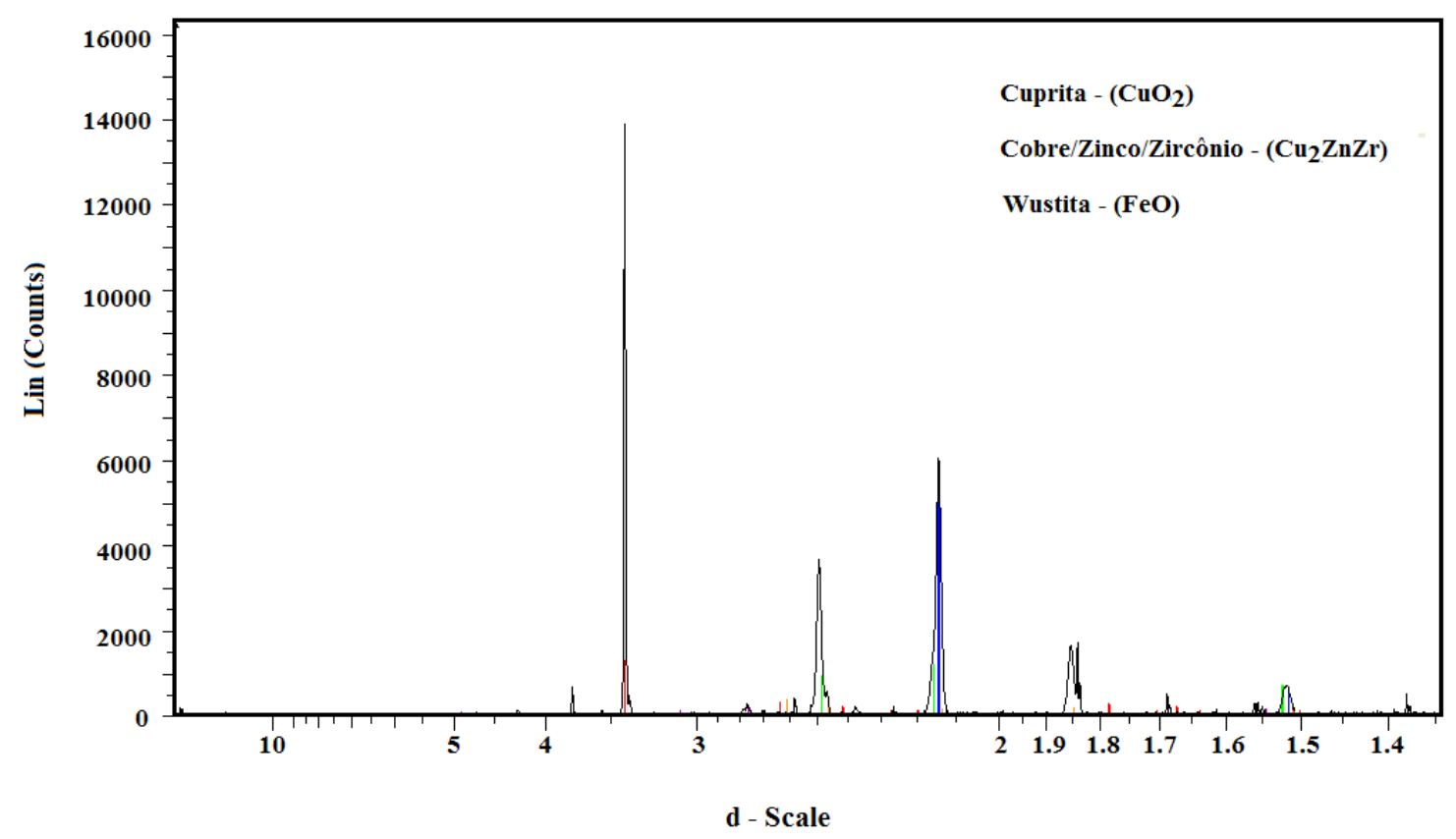

Figura 24 - Difratograma $(\mathrm{Cu} \mathrm{K} \alpha)$ referente ao Botão. Foram identificadas as fases cobre, cuprita, zinco, e wustita

Foram identificados picos que correspondem possivelmente às fases cobre, cuprita, zircônio, zinco e Wustita. Conforme foi visualizado no microscópio estereoscópico, a região de coloração avermelhada corresponde à cuprita $\left(\mathrm{Cu}_{2} \mathrm{O}\right)$. 


\section{CONSIDERAÇÕES FINAIS}

O uso de variadas técnicas analíticas não invasivas contribuiu para a preservação dos artefatos estudados. Possibilitou caracterizar, reconstruir a morfologia original, revelar informações encobertas pelos produtos de corrosão, identificar técnicas de fabricação e grau de deterioração. Através dessas informações, pode-se elaborar uma proposta mais adequada de como realizar o tratamento, acondicionamento e exposição dos artefatos. Em vista disso, ressalta-se a importância de estabelecer um bom diálogo entre os operadores dos equipamentos e o conservador para a melhor realização dessas análises e interpretação dos resultados. Este deverá oferecer aos operadores o máximo de informações sobre o artefato e o seu contexto, além das questões que queira resolver através das análises.

A presente pesquisa pode inferir que os artefatos estudados sejam de cobre (colchete e o crucifixo) e latão (botão), e provavelmente de procedência europeia, confirmando os dados da pesquisa histórica (CAMPOS; GRANATO. 2015). A presença de $\mathrm{P}$ nos espectros de EDS dos três artefatos pode estar relacionada com a proximidade com os enterramentos, o que é prejudicial para a conservação dos mesmos. Nenhuma das peças tem a camada original totalmente preservada, apresentando alterações nas suas morfologias. No entanto, as radiografias realizadas apontam que os artefatos não estão inteiramente mineralizados. A presença de nantoquita no colchete indica que o material está em condições instáveis e, por isso, deve ser acondicionado separadamente dos outros materiais e mantido em uma UR abaixo de 35\% (LOGAN, 2007) ou até 15\% (NATIONAL MUSEUM OF ICELAND, 2012).

Destaca-se a importância da caracterização do artefato antes da limpeza mecânica ou apenas que sejam realizadas leves escovadelas para retirar o excesso de sedimento, pois uma limpeza mais invasiva poderia ocasionar perda de informações importantes, a partir de fragmentos que seriam removidos, como o exemplo do possível recobrimento de prata identificado no colchete.O crescimento do produto de corrosão não é linear com o tempo e a sua formação pode ocorrer em algumas centenas de anos, pela interação da composição do metal com as condições de contorno. Dessa forma, pode-se deduzir que os produtos de corrosão dos artefatos estudados constituem período razoável de tempo, compatível com a datação relativa do sítio arqueológico.

As técnicas arqueométricas aqui empregadas contribuíram para a identificação dos artefatos arqueológicos metálicos que, de outra forma, não seria possível caracterizá-los a olho nu, evidenciando a importância da sistemática de um trabalho experimental.

\section{Agradecimentos}

Os autores agradecem o apoio do Conselho Nacional de Desenvolvimento Científico e Tecnológico - CNPq - e da Fundação Carlos Chagas de Amparo à Pesquisa, no Estado do Rio de Janeiro - FAPERJ - para o desenvolvimento das pesquisas, assim como às instituições que colaboraram para esses estudos, possibilitando a realização das diversas análises (CETEM, PUC-Rio, COPPE/UFRJ). 


\section{REFERENCIAS}

ANTELO, Tomas; BUESO, Mirim; GABALDON, Aracel; COSTEA, Antonio Martin. La técnica radiográfica en los metales históricos. Madrid: IPCE, MINISTERIO DE CULTURA, 2010.

BERTHOLON, Régis. Archaeological metal artefacts and conservation issues: long-term corrosion studies. In: DILLMANN, P.; WATKINSON, D.; BÉRANGER, G.; PICCARDO, P.; MATTHIESEN, H. (Orgs.). Corrosion of Cultural Heritage Metallic Artefacts. Number 48. Cambridge: European Federation of Corrosion Publications, 2007. p. 31-40

BRADLEY, Susan M.. Do objects have a finite life? In: KNELL, Simon. Care of Collections. Leicester Readers in Museum Studies, London: Routledge Ed., chapter 6, 1994. p. 51-59.

CAMPOS, Guadalupe do Nascimento; GRANATO, Marcus. A Preservação de Coleções Científicas de Objetos Arqueológicos Metálicos. In: GRANATO, Marcus (Org.). Museologia e Patrimônio. Série MAST: 30 anos de pesquisa, v.1. Rio de Janeiro: Mast, 2015. p. 269-298.

CAMPOS, Guadalupe do Nascimento; GRANATO, Marcus. Cartilha de Orientações Gerais para Preservação de Artefatos Arqueológicos Metálicos. Rio de Janeiro: MAST, 2015.

CARVAlHO, Orlindo José. Templos Católicos do Rio de Janeiro - Manual. Rio de Janeiro: Leitura Dinâmica Distribuidora de Livros LTDA., 2009.

CHILDS, Terry S.; SULLIVAN, Lynne P.. Curating Archaeological Collections: from the field to the repository. Oxford: Altamira Press, 2003.

CILIBERTO, Enrico; SPOTO, Giuseppe (Eds.). Modern Analytical Methods in Art and Archaeology. Chemical Analysis. In: WINEFORDNER, J. D. (Ed.). Chemical Analysis. A Series of Monographs on Analytical Chemistry and its Applications, v.155, New York: John Wiley \& Sons, Inc., 2000.

COARACY, Vivaldo. Memórias da Cidade do Rio de Janeiro. Quatro Séculos de Histórias. 1ª Edição, Rio de Janeiro, 2008.

COSTA, Virginia. Ligas Metálicas: Estrutura Propriedades e Conservação de Objetos Culturais. In: SILVA, Armando Coelho Ferreira da; HOMEM, Paula Menino (Orgs.). Ligas Metálicas Investigação e Conservação. Porto: Universidade do Porto, 2008. p.15-28.

CRONYN, Janey M. The Elements of Archaeological Conservation. London: Routledge, 2001.

JONES, David M.. Guidelines on the X-radiography of archaeological metalwork. English Heritage, 2006. Disponível em: $<$ https://content.historicengland.org.uk/images-books/publications/x-radiography-of-archaeological-metalwork/ xradiography.pdf/>. Acesso em: 10 mai. 2018.

HOBBS, Richard; HONEYCOMBE, Celia; WATKINS, Sarah. Guide to Conservation for Metal Detectorists. Charleston, SC: Tempus Publishing Ltd. 2002.

LAGO, Dalva C. B. do; MIRANDA, Luiz R. M. de; CHÃ, Michelle S. V.; VIANA, Leonardo S. Estudo de revestimentos para monumentos de bronze expostos à atmosfera da cidade do Rio de Janeiro, julho de 2005. In: GRANATO, Marcus (Org.). Congresso Latino-Americano de Restauração de Metais, 2., 2005, Rio de Janeiro. Anais.... Rio de Janeiro: MAST, 2005, p. 119-131. Disponível em: <http://www.mast.br/pdf/anais_2_congresso_latino_americano_de_restauracao_de_metais.pdf $>$. Acesso em: 14 mai. 2018.

MEYER-ROUDET, Hélène. A la recherche du metal perdu. Nouvelles technologies dans la estauration des métauxarchéologiques. Paris: Editions Errance, 1999. 
MURDOCK, Cynthia; JOHNSON, Jessica; SULlIVAN, Brigid. Curatorial Care of Archeological Objects. In: Appendix I: National Park Service Museum Handbook, Part I - Museum Collections, NPS, Washington, DC, 2001. p. 01-15. Disponível em: <https://www.nps.gov/museum/publications/MHI/AppendI.pdf>. Acesso em: 30 abr. 2018.

NATIONAL MUSEUM OF ICELAND. Guidelines on the Care of Archaeological Artefacts. Pjóðminjasafn Íslands, 2012. PAÏN, Silvia. Conditionnementet Stockage À Long Terme des Collections. Service archéologique départemental des Yvelines (SADY), 2012. Disponível em: <http://archeologie.yvelines.fr/IMG/pdf/tableau_stockage.pdf $>$. Acesso em: 28 abr. 2018.

PEDELI, Conrrado; PULGA, Stefano. Conservation Practices on Archaeological Excavation. Principles and Methods. Los Angeles: The Getty Conservation Institute, 2013.

RODGERS, Bradley A..The Archaeologist's Manual for Conservation: A Guide to Non-Toxic, Minimal. Intervention Artifact Stablization. New York: Kluwer Academic/Plenum Publishers, 2004.

ROBBIOLA, Luc; HURTEl, Loïc-Pierre. Standard nature of the passive layers of buried archaeological bronze: The example of two Roman half-length portraits. In: METAL 95: International Conference on Metals Conservation, MacLEod I., Pennec S. \& Robbiola L. Editors, London: James \&James Science Pub., 1997. p. 109-117.

ROTROFF, Susan I.. Archaeologists on Conservation: How Codes Of Archaeological Ethics And Professional Standards Treat Conservation. JAIC, v.40, p.137-146, 2001.

WATKINSON, David. Preservation of metallic cultural heritage. In: COTTIS, R. A. (Ed.). Shreir's Corrosion. 4th ed., v. 4. London: Elsevier, 2010. p. 3307-3340

SCHWEIZER, François. Bronze Objects from Lake Sites: From Patina to "Biography". In: SCOTT, David A.; PODANY, Jerry; CONSIDINE, Brian B. (Orgs.). Ancient \& Historic Metals: Conservation and Scientific Research. Edited by, Getty Conservation Institute, 2007. Disponível em: <http://d2aohiyo3d3idm.cloudfront.net/publications/virtuallibrary/0892362316.pdf>. Acesso em: 10 mai. 2018.

SCOTT, David A.. Copper and Bronze in Art: Corrosion, Colorants, Conservation. Los Angeles: Ed. The Getty Conservation Institute, 2002.

SELWYN, Lyndsie. Metals and Corrosion: a handbook for the conservation professional. Canada: Canadian Conservation Institute, 2004.

SMITH, W. F. Principios de Ciência e Engenharia de Materiais. 3.ed. Lisboa: McGraw-Hill, 1999.

Recebido em: 12/05/2018

Aprovado em: 06/08/2018

Publicado em: 30/11/2018 